\title{
The effect of culture on the fertility decisions of immigrant women in the United States
}

\author{
Miriam Marcén ${ }^{1}$, José Alberto Molina ${ }^{1,2}$ and Marina Morales ${ }^{1}$ \\ ${ }^{1}$ Universidad de Zaragoza, Zaragoza, Spain \\ ${ }^{2}$ Institute for the Study of Labor (IZA), Bonn, Germany
}

\begin{abstract}
This paper examines whether culture plays a role in the number of children born. We use data on immigrant women who arrived in the United States when younger than age six. Since all these women grew up under the same laws, institutions, and economic conditions, then the differences between them by country of origin may be due to cultural differences. We identify the cultural effect, exploiting variations in the mean number of children born by country of origin, age, education level, and employment status. Results show that the home-country mean number of children born has a positive relationship to the number of children born of immigrants living in the US, suggesting that culture is important. Additionally, we extend this work to an analysis of both the decision to have children and the number of children born, finding again that culture appears to play a significant role.
\end{abstract}

Keywords: Culture, Immigrants, Number of children born

JEL Codes: J13, Z13

Corresponding Author: Miriam Marcén

Universidad de Zaragoza

Gran Vía 2

50005 Zaragoza (Spain)

mmarcen@unizar.es

\section{ACKNOWLEDGEMENTS}

This article has benefited from comments provided by Professor Sushanta Mallick and four anonymous referees. 


\section{INTRODUCTION}

How many children would you like to have? According to the World Values Survey, the response should normally be between none and three, since around $80 \%$ of the individuals who responded to that survey during the period 1981-2004 chose that as their ideal number of children. ${ }^{1}$ But how has the fertility rate evolved from the last decades of the $20^{\text {th }}$ century? As shown in Figure 1, the total fertility rate, calculated for all the countries with information on that rate, from 1980 to 2014, has fallen significantly (World Bank Data 2014) and does not appear to be bottoming out. ${ }^{2}$ In many countries, the total fertility rate has dropped to worrying levels, below the replacement rate, set at 2.1 children per woman. Even the media highlight the necessity to analyze these low levels of fertility (The Economist 2014). Several studies have explored the factors that may explain the progressive decline in the fertility rate, focusing on the increase in the participation of women in the labor market (Ahn and Mira 2002; Brewster and Rindfuss 2000; Engelhardt et al. 2004; Michael 1985), the increased opportunity cost of women's time (Becker 1981), technological progress (Galor and Weil 1996; Greenwood and Seshadri 2002), the decline in infant mortality rates (Doepke 2005; Sah 1991), the reform of the laws that have made birth control and abortion more accessible (Ananat et al. 2007; Goldin and Katz 2000, 2002; Guldi 2008), the public debt (Fanti and Spataro 2013), housing prices (Day and Guest 2016), and the introduction of reforms in divorce laws (Bellido and Marcén 2014), among others.

Although all of these factors, separately and together, can influence the evolution of fertility rates in the majority of countries, a global pattern of convergence of fertility behavior is not clearly observed (see Figure 2). Those countries with low fertility rates in 1980 maintain those low rates in 2014. The same occurs in most of the countries with high fertility rates during the1980s; their fertility rates remain high in $2014 .^{3}$ This leads us to ask whether there are social norms or cultural attitudes that affect the number of children that women decide to have, or are such economic and institutional differences the only

\footnotetext{
${ }^{1}$ In the subsequent waves of the World Values Survey, that question or a similar one has not been included.

${ }^{2}$ The total fertility rate is defined as the mean number of children that would be born alive to a woman during her life time if she were to pass through her childbearing years conforming to the fertility rates by age of a given year.

${ }^{3}$ For those countries having high fertility rates in 1980, there are more variations in the fertility rates observed in 2014, although, as we mention above, most of them have maintained high fertility rates through 2014.
} 
things that matter. In this paper, we examine the possible effect of culture on the number of children being born.

Following the definition proposed by the United Nations Educational, Scientific and Cultural Organization (UNESCO 2001), we define culture as the set of distinctive spiritual, material, intellectual, and emotional features of society or a social group. Not only does this encompass art and literature, but it also includes lifestyles, ways of living together, value systems, traditions, and beliefs. Nearly all researchers would agree that culture is an important determinant of human behavior (Giuliano 2016), but it is not easy to measure. The interrelation among institutions, economic conditions, and social norms is one source of that difficulty (Fernández 2007; Sevilla 2010). In order to isolate the impact of culture from the effect of institutions and economic conditions, we follow the epidemiological approach (Fernández 2007), by exploring the behavior of immigrant women who arrived in the US before age 6, and whose ethnicity or country of origin is known. To document the importance of the impact of culture on the number of children that women decide to have, we use dissimilarities in the number of children born by country of origin, since women's attitudes are probably similar to the preferences of their parents, forebears, and ethnic communities.

There is a growing literature analyzing the impact of culture on socio-economic and demographic variables (Fernández 2011; Giuliano 2016). Utilizing empirical strategies analogous to ours, researchers have shown the substantial effect of culture on women's labor force participation and fertility (Contreras and Plaza 2010; Fernández 2007; Fernández and Fogli 2006, 2009), self-employment (Marcén 2014), the search for a job (Eugster et al. 2017), on living arrangements (Giuliano 2007), divorce (Furtado et al. 2013), on the math gender gap (Nollenberger et al. 2016), and even on the fertility behavior of teen women (Bellido et al. 2016). We contribute to these lines of research by extending the analysis of the impact of culture on the number children born.

Our work is related to prior studies that examine the effect of culture on fertility decisions (Bellido et al. 2016; Fernández and Fogli 2006, 2009). As Adserà and Ferrer (2015) highlight, much work is still to be done to explore this relationship. They note the necessity of improving data availability. Fernández and Fogli (2009) use data from the 1970 US Census, whereas Fernández and Fogli (2006) employ the General Social Survey for the years 1977, 1978, 1980, and 1982 -1987, in both cases with almost all countries of origin being European countries. Bellido et al. (2016) include in the sample some developing countries, but using a final sample of 10 countries, using the NLSY79 and the 
NLSY97 to explore the relationship between culture and teen motherhood. In our case, we use data from the 5\% Integrated Public Use Microdata Series (IPUMS) of the 1990 US Census (Ruggles et al. 2015), which is the last Census containing information on the number of children born per woman. Using this dataset, and following Blau et al. (2013), we expand the analysis to more recent data that allows us to incorporate more individuals originating from Latin America and Asia, who represent a substantial proportion of the immigrants arriving in the US in the latest waves of the $20^{\text {th }}$ century, reducing the weight of those originating from Europe (which constitute the main sample of the prior literature). The incorporation of individuals from developing countries is interesting to check whether the cultural effect is maintained when we add those originating from countries with greater differences - not only cultural but also in markets and institutions - from the country of destination. It can be, arguably, that living in a more developed country, in our case, the US, could make the transmission of a fertility culture of a less developed country more problematic, which would decrease the importance of social norms in fertility decisions. Additionally, the utilization of more recent data permits us to examine whether the fertility culture is still observed after the changes in the participation of women in the labor force, which may affect the transmission of culture, making social norms less important than markets and institutions in the fertility decisions of women during the last decades of the $20^{\text {th }}$ century. Heterogeneity within the countries of origin is also another relevant issue which, as Adserà and Ferrer (2015) claim, can also be more precisely considered in the more recent studies of fertility culture. Prior literature (Bellido et al. 2016; Fernández and Fogli 2006; 2009) utilizes the TFR of each country of origin as the fertility cultural proxy. They use only one measure of fertility culture for each country of origin, assuming that fertility culture does not differ within each country of origin, which is a strong supposition (Adserà and Ferrer 2015). In our case, to capture the effect of culture, we utilize data from the Integrated Public Use Microdata Series International (International IPUMS), Minnesota Population Center (2015). The International IPUMS provides rich information that, in contrast to prior research on the effect of culture on fertility decisions, permits us to measure the cultural variable by age, education level, and employment status, taking into account, at least in part, the heterogeneity of women's characteristics within countries of origin, which leads to better estimations of the effect of culture. The definition of the fertility culture also generates controversy since it is possible to suppose that not only differences in fertility culture across countries are captured by the cultural proxy, the total fertility rate (TFR), but also other dissimilarities across countries (Furtado et al. 2013). To 
tackle this issue, we introduce country of origin fixed effects. This is possible because of the way in which the cultural proxy is measured by age, education level, and employment status. As before, this improves the estimates on fertility culture. In addition, we contribute to the literature by exploring the effect of culture on both the decision to have a child and the number of children that women decide to have. To the best of our knowledge, this has not been previously studied in the literature. This is not a minor point, given the considerable increase in the number of women having no children (Abma and Martínez 2006). The search for the underlying factors, such as the fertility culture, of this recent phenomenon is of importance for both researchers and policy makers.

Our findings suggest that culture is an important factor in determining the behavior of women, even after including the socio-economic characteristics of women and measures of human capital, as in Fernández and Fogli (2009). We find that there is a positive and statistically significant relationship between the number of children born to immigrant women in the US, and the mean number of children of their counterparts in their respective countries of origin. The estimated coefficients are maintained when the husband's characteristics are incorporated, following Fernández and Fogli (2009). Our results are unaffected after controlling for unobservable characteristics of the countries of origin, including country of origin fixed effects, and using different subsamples, even after using data from different US Censuses (1970 to 1990). This provides additional evidence that our estimates are identifying the effects of culture, rather than the impact of unobserved individual characteristics that can be correlated within ethnic groups. The findings are invariant to a redefinition of culture using information from the World Values Survey. The effect of culture is also detected in the analysis of both the decision to have a child and the number of children that women decide to have, using double hurdle models.

In the final section, we study the horizontal transmission of culture, following Furtado et al. (2013). Culture is not only transmitted from parents to their children, but also within the communities in which women live (Fernández and Fogli, 2009). Unfortunately, we cannot directly analyze how the intergenerational transmission of culture operates from the information provided by the Census. Nevertheless, it is possible to explore the horizontal transmission, following a network approach. We can interpret a positive relationship between an increase in the concentration of individuals of the same ethnicity and the number of children born to immigrant women, as evidence of the existence of a horizontal transmission of culture. If the effect of this horizontal 
transmission is not quite significant, it could be suggested that the intergenerational transmission of culture does play a more important role.

The remainder of the paper is organized as follows. Section 2 describes the data, Section 3 presents the empirical strategy, our results are discussed in Section 4, and Section 5 concludes.

\section{DATA}

We use data from the 5\% IPUMS of the 1990 US Census, which is the last Census with information on the number of children born. Our sample selection consists of immigrant women living in the US, aged 16 to 46 years old, who arrived in the US aged 5 or younger, and who report their country of origin. ${ }^{4}$ Since the preferences and attitudes of these immigrant women are likely to be similar to those of their parents and ethnic communities, it is possible to interpret any dissimilarity in the mean number of children born by country of origin as supporting evidence of the importance of culture. Our main sample contains 5,726 observations of immigrant women, originating from 26 countries. ${ }^{5}$

We have chosen first-generation immigrants, although most of the prior literature analyzing the effect of culture on several variables mainly uses information on secondgeneration immigrants who are unlikely to suffer language barriers or the immigration shock (Fernández 2007; Fernández and Fogli 2006, 2009; Furtado et al. 2013; Giuliano 2007). Unfortunately, second-generation immigrants cannot be incorporated in our sample, because the last year for which the Census provides information about the country of origin of parents is 1970. As explained above, we prefer to use more recent data, improving data availability, as Adserà and Ferrer (2015) suggest, to be able to study whether social norms are less important than markets and institutions in fertility decisions, when women from less-developed countries are added to the analysis, and whether the cultural effect is maintained after the extensive incorporation of women in the labor force during the last decades of the $20^{\text {th }}$ century. As Furtado et al. (2013) maintain, our sample of young immigrant women arrivals can be considered quite similar to a sample of secondgeneration immigrants because of their early migration process. The laws and institutions

\footnotetext{
${ }^{4}$ We have eliminated those countries of origin with less than 10 observations per country, as in prior studies. It is also worth noting that the analysis has been repeated by selecting a sample of immigrant women who arrived in the US under age 11, and results are similar. We can only select women younger than 47 years old because the IPUMS USA only contains information on the number of children born to women younger than 47. Note that the sample is limited to those living in MSAs.

${ }^{5}$ We incorporate women who decide to have children. We revisit this issue below by repeating the analysis including those who do not have children.
} 
of their home country are unlikely to have influence on an individual younger than 6 , and the language barriers and the shock of the immigration are not likely to be lasting (Furtado et al. 2013), as young migrants are capable of quickly adapting to a new place of residence.

The cultural proxy is defined as the home-country mean number of children born. The data come from the microdata of the Censuses (IPUMS International) (see Appendix). As mentioned above, our measure of culture differs from that utilized in prior literature where the total fertility rate is the cultural proxy. In that setting, it is implicitly assumed that all women originating from a specific country have the same fertility culture, regardless of their age, level of education, or employment status. So, for example, this would imply that having no children is equally acceptable for young women as for those at the end of their fertility years, or having few children is equally acceptable to society for those women with a high level of education, or who are employed, as for those with a low level of education, or those who are inactive in the labor market. As mentioned above, this is a strong assumption, since, even in a country in which the social norm is that women should have many children, it is possible to argue that the fertility culture differs depending on women's characteristics, as Bellido et al. (2016) show for the case of teen motherhood. For this reason, we prefer to build our cultural proxy using data from the country of origin Censuses, which allows us to consider possible fertility-cultural differences by age, education level, and employment status. Therefore, if culture varies depending on the specific characteristics of women, we should observe dissimilarities in our estimates, depending on the way in which that variable is measured.

Table 1 presents summary statistics for the relevant variables, ordered from the lowest to the highest home-country mean number of children born. As can be seen, there are considerable differences among countries of origin: from 2.14 children per woman in Hungary, to 4.84 children per woman in Morocco, which may point to the existence of cultural differences in fertility behavior. ${ }^{6}$ The rest of the columns describe the main sample. Immigrant women have 2.03 children in the US on average, with those originating from China and Hungary having the highest number of children. Surprisingly, comparing these two columns, we cannot deduce a clear relationship between the variable that measures the effect of culture and the number of children born to immigrant women in the US. Divergences in fertility behavior appear to be notable for those immigrant women

\footnotetext{
${ }^{6}$ To calculate the mean number of children born by country of origin, we have excluded those women having no children.
} 
having more than two children. However, for those immigrant women having fewer than two children, the relationship appears to be clearly positive: the greater the number of children in the home country, the more children immigrant women originating from that home country have in the US (see Figure 3). Although the differences detected in those summary statistics could be due to dissimilarities in the transmission of culture, or in the effects of culture, it should be noted that the composition of the immigrant women sample by country of origin can be driving the differences in their fertility decisions. Overall, the age of the women in our sample is around 30 years old, on average, with the youngest women originating from El Salvador and Thailand, 20 years old on average, and with the oldest being from Austria and China, more than 35 years old on average. This age gap in the structure of immigrant women by country of origin can be a little problematic in analyzing the effect of culture on the number of children born, since some of the women are at the beginning of their reproductive life, while others are near the end of that stage. Thus, the introduction of controls for the age of women is necessary to address this issue. There is an additional problem that the age gap can generate. It can be surmised that attitudes towards fertility behavior could vary, not only across countries but also across age groups within countries. ${ }^{7}$ In one country, it may be socially acceptable to have children when women are young, while in others it may be less acceptable. To explore the potential cultural differences by age, we redefine the culture variable as the mean number of children born, by country of origin and age group, with the age groups being: 20 to 29, 30 to 39 , and 40 to $46 .{ }^{8}$ Within this framework, rather than calculating only one measure of the cultural proxy for each home country, we are able to incorporate three measures of fertility culture for each country of origin.

The differences in the level of education of immigrant women by home country may also provoke concerns on how, and on whom, the fertility culture may play a role. Averaged across countries of origin, 33\% have completed High School, ranging from a low of $13 \%$ for Iran and Venezuela, to a high of $40-42 \%$ for Ecuador and Spain. With respect to those who have some college education, that is, 1 to 3 years of degree studies, and more college, that is, 4 and more years of degree studies, the lowest percentages are

\footnotetext{
${ }^{7}$ For example, in Argentina and Colombia, women tend to have a similar number of children when they are young, but there are considerable dissimilarities between those two countries for women aged 40 to 46: those in Argentina have around 3 children on average, while those in Colombia have more than 4 children.

${ }^{8}$ We do not include in that analysis those immigrant women under age 20 because the number of observations is very small for that age group. For consistency, all our estimates have been repeated without those women and our results are similar. The effect of fertility culture on teen motherhood is examined in Bellido et al. (2016).
} 
observed among those originating from Mexico, Thailand, and El Salvador (less than 35\%), and the highest among those from Iran, Peru, and Haiti (more than 70\%). Since, normally, less-educated women tend to have more children than better-educated women (Barro and Becker 1988; Willis 1973), the incorporation in our work of controls on education is necessary. Nevertheless, we should remember that, in this setting, the attitudes to fertility may also vary, depending on the level of education of women within each country. For example, in one country it may be more socially acceptable for a woman to have few children if her education level is high, but this may be less acceptable for a woman with a low education level. Again, to tackle this issue, we redefine the cultural proxy as the mean number of children born by country of origin, age, and education level. As we do for the education level, we repeat the same analysis with the mean number of children calculated by country of origin, age, and employment status (employed, unemployed, and not in the labor force).

Regarding the number of observations, differences across countries of origin are detected in the last column of Table $1 .^{9}$ Those originating from Mexico and Germany represent a significant part of all our observations. With respect to the Mexican women, the existence of a large number of Mexican migrants living in the US is not surprising, because of proximity of those countries (Durand et al. 1999). However, the large number of German women in our sample is somewhat more striking. It is worth noting that this extensive German immigrant sample is also observed in other studies, using similar samples of early-arrival first-generation immigrants (see, for example, Furtado et al. 2013). A possible explanation for the German immigrant group could be the massive immigration of Germans to the US during the post-World War II period (Münz and Ulrich 1997; Tempo 2008). The Displaced Persons Act of 1948, which authorized the admission into the United States of certain European displaced persons for permanent residence, for victims of persecution by the Nazi regime, and for those fearing persecution based on race, religion, or political opinions, facilitated the migration of many Germans to the US. Bearing in mind the dissimilarities in the number of observations, this does not appear to be a major problem, since we repeat the analysis, removing Mexican and German women, to check whether this is driving our findings and our results do not vary as we explain in detail in section 4.

\footnotetext{
${ }^{9}$ Note that the number of observations presented in Table 1 come from the raw data, but that we use weights in all our estimates shown in the rest of the Tables.
} 


\section{EMPIRICAL STRATEGY}

Following the epidemiological approach, our empirical strategy is based on the fact that immigrant women who arrived in the US when very young have all lived under the same US market conditions and institutions. Thus, if only institutions and markets are important in the fertility decisions of women, we would expect no effect of the home-country mean number of children of their counterparts on the number of children that those immigrant women have in the US. On the other hand, if culture does play a role in the decisions of immigrant women, we would expect to observe that the home-country mean number of children does have an effect on the number of children that immigrant women have in their host country, the US. Formally, we analyze this issue by estimating the following equation:

$$
Y_{i j k}=\beta_{0}+\beta_{1} H C C E B_{j}+X_{i j k} \beta_{2}+\delta_{k}+\varepsilon_{i j k}
$$

where $Y_{i j k}$ is the number of children born to woman $i$, whose country of origin is $j$ and lives in state $k$. Our measure of culture, $H C C E B_{j}$, is the mean number of children born in the home country $j$. We revisit the definition of the cultural variable and its implications below. In any case, if culture really matters, women from countries whose counterparts have many children should maintain a similar behavior, having many children in their host country, whereas those women, whose counterparts in their home country have fewer children, should also have fewer children. Then, we would expect $\beta_{1}$ to be positive. $\boldsymbol{X}_{i j k}$ includes women's individual characteristics, which may have an impact on the number of children for reasons other than culture, such as age or education (Leon 2004). We control for the unobservable differences across US states by introducing state fixed effects, denoted by $\delta_{k} \cdot{ }^{10}$ Standard errors are clustered at the home country level to account for any within-ethnicity correlation in the error terms. ${ }^{11}$

With this empirical strategy, we can only examine the impact of culture on the number of children born. We note that our work is not limited to the analysis of that relationship only, since we also focus on the decision to have children. To address this

\footnotetext{
${ }^{10}$ We have re-run the entire analysis using Metropolitan statistical area (MSA) fixed effects, and we find no substantial differences in our results.

${ }^{11}$ All estimates have been repeated with/without weights and with/without clusters. Results do not vary.
} 
issue, we utilize double hurdle models that permit us to study the effect of culture on the decision whether or not to have children, and, for those who do decide to have children, we can analyze the impact of culture on the number of children born. This methodology is discussed in detail in Section 4.

\section{RESULTS}

\section{a. Baseline Model}

Table 2 presents the estimated coefficients for our main specification, including age and education controls, equation (1), and with the cultural proxy defined as the home-country mean number of children born. As can be observed in column 1, a higher mean number of children born in an immigrant's home country is related to an increase in the number of children that the immigrant women decide to have. The cultural effect, although it is statistically significant, appears to be quite small, since if the home-country mean number of children born increases by one, there is an increase of almost 0.08 children born to the immigrant women. Comparing countries of origin, immigrant women from countries where their counterparts have few children (for example, Hungary, Germany, or Austria), would have 0.21 fewer children, because of the impact of culture, than those immigrants whose counterparts have a large number of children in their home countries (Morocco, Nicaragua, or Mexico). While the effect of culture would be around 0.16 children per woman in the first case, it would be approximately 0.37 in the second case.

As expected, the older the immigrant women, the more likely are those women to have a greater number of children. The impact of age appears to have an inverted U-shape, achieving the maximum at 47 years old. Note that our immigrant women are all aged below the age of 47 . The estimates for the education level controls are consistent with the literature, since the higher the level of education, the lower the number of children that women decide to have. As the existing literature shows, this occurs because of the increase in the opportunity costs of time for those more educated individuals (Barro and Becker 1988; Willis 1973), and/or because of the negative effect that having a high level of education can have on the age at first marriage of women (Breierova and Duflo 2004), which, in turn, delays childbearing and reduces the possibilities of having a large number of children (Kalwij 2000). In the second column, state fixed effects are added to control for unobservable characteristics that may vary at the state level. Column 3 includes Metropolitan Statistical Areas (MSAs) fixed effects, rather than state fixed effects, to 
capture the unobservable characteristics. ${ }^{12}$ In both cases, we still find a positive association between the home-country mean number of children born and the number of children that the immigrant women give birth to, but the effect of culture is even smaller than that obtained before, and it is only statistically significant at the $10 \%$ level. The minor role of culture in fertility may indicate that those estimates are not well-capturing the impact of culture on fertility. This may be due to the fact that the age structure of the sample of immigrant women is different from that of their counterparts in their respective countries of origin. To tackle this issue, we repeat the analysis, considering a sample of women aged 40 to 46 years old, in which we mitigate the concerns that a different age structure of the immigrant sample could generate. Those women aged 40 to 46 constitute an interesting sample in our analysis, since they are all near the end of their reproductive lives, so variations in the number of children born would be expected to be quite insignificant. In this situation, we can explore the effect of culture at the end of the reproductive period of women. Results are shown in Table 3, in column 1 (with the homecountry mean number of children born measured as in Table 2) and column 2 (with the home-country mean number of children born calculated for women aged 40 to 46). We find that the impact of the cultural proxy, regardless of the measure utilized, remains statistically significant and positive, with the magnitude of the cultural effect being more than $60 \%$ greater, pointing to a more important role of culture in fertility decisions when the sample of older women is considered.

Another way to examine the potential age structure problem is by utilizing several measures of culture, one for each age group (20-29, 30-39, and 40-46) and country of origin. In this way, rather than calculating only one measure of the cultural proxy for each home country, we incorporate three measures of the fertility culture for each country of origin: one cultural proxy is used for those women aged 20 to 29, another is calculated for those women aged 30 to 39, and we use another for those women aged 40 to 46 . This analysis is necessary to take heterogeneity within countries into consideration. Culture can vary not only by country of origin, but also depending on women's characteristics in each country of origin. For example, in countries with similar general fertility behavior (such as having fewer children), it is possible to argue that the effect of culture varies depending on the age of women, with some countries having more acceptable attitudes towards women

\footnotetext{
${ }^{12}$ IPUMS USA defines a metropolitan area as a region formed by neighboring communities that have a high degree of economic and social integration with the urban core. The population threshold to identify an MSA is 100,000 inhabitants.
} 
having children when young, while, in certain other countries, young women having children may be ostracized. Columns 4 and 5 report the estimates with this new measure of culture, with the home-country mean number of children born being calculated by country of origin and age group (20-29, 30-39, 40-46). To run this analysis, we have excluded those individuals younger than age 20, because of the availability of observations. To easily compare the results, column 3 reports the estimates using the previous definition of culture, home-country mean number of children, but for the same sample as used in columns 4 and 5, individuals aged 20 to 46 . We also note that the use of the new definition of culture, that includes three measures of fertility culture by country of origin, permits us to add country of origin fixed effects. This is important because one of the main problems found in prior papers on the impact of culture is that they do not incorporate those fixed effects by country of origin, without which there can be concerns about exactly what is being picked up by the estimated coefficient on the cultural proxy. That coefficient could be capturing the effect of culture on fertility in addition to, or instead of, the impact of other unobservable characteristics that vary at the home country level, and that also affect fertility decisions. It is comforting that, even after adding those home-country fixed effects, our findings are unaffected, the cultural proxy has a positive impact on the number of children born, and the magnitude of the effect has considerably improved, by almost $80 \%$ with respect to that presented in column 3 of Table 3 . Then, these estimates provide additional evidence suggesting that we are, in fact, capturing the impact of culture on the number of children that women decide to have.

Apart from differences in the age structure, dissimilarities in the education and employment status may be important in determining the effect of culture on fertility. Within the same country of origin, for women with higher levels of education, it may be socially more acceptable to have fewer children than those who are less well-educated. We tackle this issue by redefining, again, our cultural proxy, taking into consideration the possible fertility-cultural differences by education level within the same country. The results are shown in the first column of Table 4, which corresponds to the specification of a model in which the culture variable is calculated as the mean number of children born in the country of origin, by age and education level. Twelve different measures of fertility culture for each country of origin are reckoned, depending on whether women are aged 20 to 29, 30 to 39 or 40 to 46, and on whether women have not completed High School, have completed High School, have studied 1 to 3 years of college studies, or 4 or more years of college studies. The estimated coefficient on the cultural proxy is positive and statistically 
significant, indicating that culture plays an important role in the decision of the number of children to have. Since the sample varies because of the availability of information on the education variable in some countries of origin, we re-run the analysis considering the same sample as in column 1, but using the cultural proxy of Table 2. The estimates are displayed in column 3 , showing that the magnitude of the effect is greater after redefining the cultural proxy by age, education level, and country of origin. The effect of culture on the number of children born is maintained, even after adding the fixed effects at the country of origin level (see column 2).

In the specifications in columns 4 and 5 of Table 4, our variable of interest is defined as the home-country mean number of children born, by age and employment status, so we have nine different measures of fertility culture by country, depending on the age group (20-29, 30-39, 40-46) and the employment status (employed, unemployed, or inactive). As above, we run those specifications to account for possible dissimilarities in the fertility culture by age and employment status within each country of origin. We find that, with or without the country of origin fixed effects, there is a positive and statistically significant association between the cultural proxy and the number of children born to immigrant women. Again, the magnitude of the effect of culture on the number of children born is considerably higher than that obtained when the cultural proxy does not take into account the possible cultural differences within countries (see column 6). The same is observed when the sample is limited to those aged 40 to 46 years old, in columns 7 and $8{ }^{13}$ After redefining the cultural proxy to incorporate the heterogeneity with respect to women's characteristics within countries, we observe an increase in the magnitude of the culture effect in all cases, suggesting that the differences within countries should be taken into account when analyzing the role that culture plays in fertility decisions.

In terms of robustness, we consider whether our findings are maintained when measuring the cultural proxy in different years, when utilizing different subsamples, and when incorporating additional observable characteristics at the country of origin level. Results are reported in Tables 5 and 6. In all previous specifications, we have obtained the cultural proxy from the International IPUMS, using information on the country of origin for the year 1990, or the closest available, based on the notion that immigrant women living in the US in 1990 behave similarly to their counterparts in their country of origin in

\footnotetext{
${ }^{13}$ Note that the sample of women aged 40 to 46 has considerably decreased compared to the estimates shown in Table 2. In any case, it should be remarked that this change in the number of observations does not drive our results. It is the variation in the definition of the cultural proxy (incorporating the heterogeneity within countries) which appears to improve the magnitude of the cultural effect on fertility decisions.
} 
that year. ${ }^{14}$ Nonetheless, since culture is transmitted from parents to their offspring when they are young, it can be argued that the behavior of immigrant women is quite similar to that of their parents when they had their children, so the cultural proxy should be measured some decades before. Since our women are 30 years old on average in 1990, we use information on the 1970s as a proxy of the culture that their parents transmitted. As Fernández (2007) explains, culture changes very slowly, so we should observe similar results by measuring the cultural proxy in different years. That is, in fact, what we find; our results do not change (see the first column of Table 5). ${ }^{15}$ It is also possible to conjecture that the relationship between the cultural proxy and the number of children born depends on the US Census used. A change in the composition of respondents over time may lead to different conclusions. To address this issue, we incorporate earlier Censuses in our analysis. This gives us a larger sample of immigrant women and mitigates the cross-sectional concerns that the use of only the 1990 US Census may generate. We extend our sample to include information from the 1970, 1980, and 1990 US Censuses. ${ }^{16}$ The estimates are presented in the second column of Table $5 .{ }^{17}$ It is reassuring that, after adding several US Censuses, the effect of culture is still detected. The home-country mean number of children born by country of origin and year is positively related to the number of children born of immigrant women. Then, the possible changes in the composition of the immigrant women sample over time do not appear to lead to different findings. As simple robustness checks, we repeat the analysis without the two countries with the highest and the lowest home-country mean number of children born (Hungary and Morocco) to check whether this is driving our estimates. Results can be observed in columns 3 to 6 of Table 5, with all the definitions of the cultural proxy. Our findings do not vary. Furthermore, in column 7, we have removed those women originating from China, since that country has legislation that imposes limits on the number of children

\footnotetext{
${ }^{14}$ We also run the entire analysis without those immigrants with no information on their country of origin close to the year 1990 (for example, Iran 2006; see Appendix). Results are unaffected.

${ }^{15}$ The variation in the sample size is due to the availability of information for the 1970s. The home-country mean number of children born can only be calculated for 21 International Censuses of 1970 (those containing information in the 1970s) in column 1.

${ }^{16}$ Data come from the $1 \%$ microdata of the 1970 US Census (796 observations, 21 countries of origin), the $5 \%$ microdata of the 1980 US Census (1,718 observations, 32 countries of origin), and the $5 \%$ microdata sample of the 1990 US Census (5,726 observations, 26 countries of origin). In the case of the 1970 US Census, the number of observations is low, because we are using only the available $1 \%$ of the Census for that year. In the 1980 Census, it is possible to utilize $5 \%$ of the Census but, although the number of countries of origin is greater than in other Censuses, the observations available are not as numerous as those obtained with the 1990 US Census. The final sample consists of 8,240 observations. The measure of culture is defined by country of origin as in Table 2 (see Appendix).

${ }^{17}$ The measure of culture is defined by country of origin as in Table 2 using information on the country of origin for the corresponding year, or the closest available (see Appendix).
} 
born per woman, which can affect the measure of the fertility culture of that country, for reasons independent of social norms. We have also eliminated those immigrant women from Mexico and Germany, that is, the countries with the largest number of observations, and without Chinese women, in the last column of Table $5 .{ }^{18}$ Results remain similar regardless of the sample used. We can draw the same conclusions when we add additional controls for observable characteristics of the countries of origin in Table 6. We introduce GDP per capita (in constant 2005 US \$), female labor force participation, the total fertility rate, and the unemployment rate. It is worth noting that the inclusion of the total fertility rate, which is a measure of fertility behavior in other studies, does not alter our estimates. Although all our results appear to be robust, there can still be a suspicion that unobserved human capital can be driving our conclusions. As Fernández and Fogli (2009) suggest, it can be argued that, even after controlling for a woman's education, if the unobserved human capital varies with the country of origin in a way that is correlated with the cultural proxy, this could explain the observed correlations. For example, the human capital embodied in an ethnic group may facilitate the use of contraception methods differentially, depending on the country of origin, which can affect the number of children born. To take this into account, we add to our analysis an index of human capital by country of origin and age group based on the average years of schooling, from Barro and Lee (2013), as a proxy of unobserved human capital. ${ }^{19}$ As can be seen in Table 6, columns 1 to 4, regardless of the measure of the cultural proxy, the estimated coefficients do not change substantially after adding all those additional controls. To provide more empirical evidence that we are capturing the effect of culture, following Furtado et al. (2013), we have redefined the cultural proxy using a different dataset, the World Values Survey (WVS). This dataset includes questions related to the preferences and beliefs of the individuals that permits us to measure the attitudes towards fertility in each country of origin. Instead of using the home-country mean number of children born as cultural proxy, we propose the utilization of the home-country mean ideal number of children by country of origin, obtained from the WVS, since it can be considered as a measure of the preferences of the individuals with respect to the fertility culture. The estimated coefficients are displayed in columns 5 and 6 of Table 6. Even with this redefinition of the

\footnotetext{
${ }^{18}$ We note that all the estimates in which the cultural proxy is defined by age and employment status exclude women originating from Germany, because the German Census does not contain information on that variable (as the rest of the International Censuses do). Without those individuals, results are maintained, as can be seen in our robustness checks.

${ }^{19}$ We are able to use seven different measures of unobserved human capital for each country of origin.
} 
cultural proxy, our estimations appear to reveal the existence of a cultural effect on fertility. We find that a higher mean ideal number of children in an immigrant's home country is related to an increase in the number of children that the immigrant women decide to have, regardless of the controls included.

As explained above, the 1990 US Census (Ruggles et al. 2015) is the last Census containing information on the number of children born per woman, but it does not provide information on the characteristics of the father of those children. Then, we cannot include controls in our analysis for the father's characteristics. This can be problematic, since several studies suggest that there is an effect of fathers' characteristics on fertility outcomes (Doepke and Kindermann 2016, 2017; Sorenson 1989; Thomson et al. 1990). Prior literature suggests, from both theoretical and empirical approaches, that both parents desires, preferences, and characteristics may play a role in having a child. In this framework, it can be surmised that the omission of father's characteristics can affect our outcomes if they are correlated with our cultural proxy through, for example, the assortative matching in marriage (Fernández and Fogli 2009). To tackle this issue, following Fernández and Fogli (2009), we add to the analysis controls for the husband's characteristics of our sample of immigrant women. We recognize that this is not the best way to measure the fathers' characteristics, since those men who are living with our immigrant women in 1990 are not necessarily the fathers of the children of those women, but, as in prior literature (Fernández and Fogli 2009), there is no alternative. Being aware of this problem, to run this analysis we choose a sample of early-arrival immigrant women who live with a partner and whose characteristics are known. ${ }^{20}$ The partner is a man who is denoted the woman's husband in Table 7. We incorporate in our analysis controls for his age, education level, and total income, as in Fernández and Fogli (2009). Results can be observed in the first column of Table 7. As in the case of the woman's characteristics, the higher the level of education of the husband, the lower the number of children born. The rest of the husband's characteristics (age and income) are not statistically significant. Although we should take all these estimates with caution, with respect to our variable of interest, the cultural proxy, our results are maintained even after controlling for husband's characteristics, which once again reinforces our findings. ${ }^{21}$ Fernández and Fogli (2009)

\footnotetext{
${ }^{20}$ In all our previous estimates, we include women with and without a partner.

${ }^{21}$ The home-country number of children born measured by age group is used here as a cultural proxy since, as we have explained, our results improve when the cultural differences by age are considered. Results do not change substantially when we calculate the cultural proxy by age and education level, and by age and employment status.
} 
also suggest that women's fertility outcomes can be influenced not only by her husband's characteristics, but also by her husband's cultural beliefs. To check this, we include in the analysis two dummy variables: Same (for same culture of both members of the couple) and Not-same (for different cultures), and we interact those dummies with the cultural proxies, following Fernández and Fogli (2009). Note that, for the US-born husbands, we use a cultural proxy of US culture, but that we have also repeated the analysis without those couples in which the man is US-born and results are maintained, although the number of observations considerably decreases. Column 2 of Table 7 presents the results using only the women's cultural proxy. As expected, the coefficients are positive and statistically significant. Column 3 incorporates only the husband's cultural proxy, whose estimated coefficients are positive but not statistically significant in the case of Not-same culture, which, again, should be taken with caution, because it can be due to the fact that we are considering immigrant women's partner, but the 1990 US Census does not specify whether they are the actual fathers of the children of those immigrant women. Column 3 uses both cultural proxies. As in Fernández and Fogli (2009), the coefficient on the women's cultural proxy is larger and statistically significant, which is not the case for the husband's cultural proxy. Thus, it appears that women's beliefs and preferences play a more important role in fertility decisions. In any case, all the results described in this section suggest that fertility culture has an impact on the number of children born.

\section{b. Having children or not and, if so, how many?}

Up to now, the analysis has been carried out considering a sample of women who have children. Thus, our conclusions would only be applicable to women who decide to have children. However, the use of a truncated sample can be problematic, since the sample of excluded women, those who have no children, has not been selected randomly. In this setting, it may be suggested that the estimated effect of culture on the number of children born is confounding both the impact of the decision to have children, and that of the number of children born.

To explore both decisions, we propose other methodologies. We first consider a Tobit model (Tobin 1958) that allows us to take into account the decision to have children, and the number of children that women decide to have. Formally:

$$
Y_{i j k}^{*}=\beta_{0}+\beta_{1} H C C E B_{j}+X_{i j k} \beta_{2}+\delta_{k}+u_{i j k}
$$




$$
\begin{aligned}
& Y_{i j k}=Y_{i j k}^{*} \quad \text { if } \quad Y_{i j k}^{*}>0 \\
& Y_{i j k}=0 \quad \text { if } \quad Y_{i j k}^{*} \leq 0
\end{aligned}
$$

where $Y_{i j k}^{*}$ is the unobservable latent variable. The rest of the variables are defined as before. Columns 1 and 2 in Table 8 show the regression results after defining the cultural proxy by age group, with/without state fixed effects, respectively. ${ }^{22}$ In both columns, the effect of the home-country mean number of children born is positive and statistically significant. This finding again indicates that immigrant women from countries with a high mean number of children born tend to have many children, whereas those from countries with a low mean number of children born tend to have few children, because of fertility cultural differences.

One key limitation of the Tobit model is that the explanatory variables have the same effect on the probability of having children, or not having children, $P\left(Y_{i j k}^{*}>0\right)$, and on the number of children, $E\left(Y_{i j k} \mid Y_{i j k}^{*}>0\right)$, which appears to be unrealistic. To tackle this issue, we explore the use of alternative, double hurdle models. As in the Tobit model, both decisions, having children or not, and how many children to have, are taken into consideration in the double hurdle models. First, we analyze the decision of women to have children, or not, and, then, among those who do decide to have children, we examine the decision of how many children to have. The first stage is defined as follows:

$$
\begin{gathered}
D_{i j k}^{*}=\beta_{0}+\beta_{1} \operatorname{HCCE}_{j}+X_{i j k} \beta_{2}+\varepsilon_{i j k} \\
D_{i j k}=1 \Leftrightarrow D_{i j k}^{*}>0 \Leftrightarrow \text { Woman i decides to have children } \\
D_{i j k}=0 \Leftrightarrow D_{i j k}^{*} \leq 0 \Leftrightarrow \text { Woman i decides to have no children }
\end{gathered}
$$

where $D_{i j k}^{*}$ is an unobservable latent variable. The second stage is defined as follows:

$$
\begin{gathered}
Y_{i j k}^{*}=\beta_{0}+\beta_{1} H C C E B_{j}+X_{i j k} \beta_{2}+u_{i j k} \\
Y_{i j k}=Y_{i j k}^{*} \text { if } Y_{i j k}^{*}>0 \text { if } D_{i j k}=1 \\
Y_{i j k}=0 \Leftrightarrow Y_{i j k}^{*} \leq 0 \text { or } D_{i j k}=0
\end{gathered}
$$

\footnotetext{
${ }^{22}$ As before, the home-country number of children born measured by age group is used here as a cultural proxy. Results do not change substantially when we calculate the cultural proxy by age and education level, and by age and employment status.
} 
This double hurdle model corresponds to a generalization of the Tobit model proposed by Cragg (Cragg 1971). Results are presented in columns 3 (first stage, having children, or not) and 4 (second stage, how many children). The cultural proxy is also defined by age group. Our results suggest that women from countries where the mean number of children is high are more likely to decide to have children than those whose counterparts in their country of origin decide to have few children. The higher the homecountry mean number of children, the higher the probability of having children, and the higher the cultural proxy, the higher the number of children that women have. Then, the impact of culture on the decision to have children is not driving our findings, since there is an effect of culture on the decision to have children, but there is also an effect on the decision of how many children to have. These results reinforce our conclusions, suggesting that culture is an important factor in the fertility decisions of women. ${ }^{23}$

\section{c. How can culture be transmitted?}

The results described earlier suggest that culture affects the number of children that women decide to have, but with that analysis we cannot determine whether culture has been transmitted horizontally, through neighbors, friends, or the ethnic communities in which immigrant women live, or vertically, through parents (grandparents or other ancestors) who probably instill values in their children. This is of concern, since it can be hypothesized that the home-country mean number of children born has no effect on the decisions of immigrant women, but that immigrants simply behave as their parents do. Thus, it can be suggested that culture does not matter, because immigrant women simply replicate their parents' behavior, as Furtado et al. (2013) explain. Unfortunately, we cannot extend our work to the study of the vertical transmission of culture because we do not have information on the parents; however, we can examine whether immigrant women's sensitivities to their home-country mean number of children differs depending on whether they live in predominantly same-ethnicity communities, as Furtado et al. (2013) suggest. This analysis is based on the idea that parents' behavior regarding fertility is the same, regardless of where they live. Under that assumption, we may interpret a stronger relationship between the cultural proxy and the own number of children born into

\footnotetext{
${ }^{23}$ Because of convergence problems in the estimations of the double hurdle models presented in columns 3 and 4 , we could not include fixed effects. In any case, the Tobit model has been estimated incorporating fixed effects and our findings do not vary.
} 
predominantly same-ethnic communities, as empirical evidence that culture is horizontally transmitted.

The possibility that the culture can be transmitted horizontally is also mentioned in Fernández and Fogli (2009), who explain that local communities can maintain culture either by providing role models for acceptable family behavior, or by punishing deviance from the social norm. To identify that horizontal transmission of culture, we consider an empirical strategy similar to that followed by Bertrand et al. (2000), and used in Furtado et al. (2013), for the analysis of network effects. Formally, we estimate the following equation:

$$
Y_{i j k}=\beta_{0}+\beta_{1} P_{j k}+\beta_{2} P_{j k} * \operatorname{HCCEB}_{j}+X_{i j k} \beta_{3}+\delta_{k}+\gamma_{j}+\varepsilon_{i j k}
$$

where $P_{j k}$ is the proportion of immigrant women from the same country of origin $j$ in each metropolitan area $k, \gamma_{j}$ represents the country of origin fixed effects, and $\varepsilon_{i j k}$ is the error term. The remaining variables have been defined above. The country of origin fixed effects capture any unobservable determinant of fertility that varies by home country.

We are interested in the interaction between the proportion of immigrant women of the same country of origin and the home-country mean number of children. If culture is transmitted horizontally, we would expect that an increase in the concentration of sameethnicity immigrants will increase the number of children more for immigrant women originating from countries with high mean numbers of children than for those from countries with low numbers of children born. Then, $\beta_{2}$ should be positive.

Table 9 reports the regression estimates. In the first column, we observe that the ethnic concentration has a negative and statistically significant effect, suggesting that the greater the concentration of individuals of the same ethnicity, the lower the number of children born. The same is observed in column 2, after including the home-country mean number of children born. The coefficient that captures the impact of the fertility culture has a positive sign, and its magnitude almost coincides with that obtained in column 5 of Table 3. To explore whether the negative effect of the proportion of individuals of the same ethnicity is maintained, regardless of the home-country mean number of children, we analyze the interaction between those two variables. When including the interaction in column 3, the coefficient picking up its effect is positive and statistically significant, as expected, so the negative relationship is not maintained for all countries. We can easily examine the results of the last column, where we exclude the home-country mean number of children born and we include the country of origin fixed effects, which allows us to 
identify the role of culture variations in the interaction between ethnic concentration and home-country mean number of children, as Furtado et al. (2013) explain. As can be observed in column 4 of Table 9, our coefficient of interest increases from 0.17 to 0.23 and remains highly significant. Focusing on a comparison across countries, for example, an increase of 10 percentage points in the concentration of German women leads to a decrease of 0.03 in the number of children that each German immigrant woman has (the mean number of children in Germany is 2.18). However, the same increase in the concentration of Mexican and Moroccan women results in an increase of 0.02 children per Mexican immigrant woman (the home-country mean number of children born in Mexico is 4.40) and an increase of 0.03 children per woman in the case of Moroccan immigrant women (the home-country mean number of children born in Morocco is 4.84). Thus, an increase in the concentration of women of the same ethnic community results in a decrease in the number of children for women from countries where their counterparts have a low number of children, while an increase in the number of children of immigrant women is observed for those from countries of origin with high mean numbers of children. The increase is greater, the greater the home-country cultural proxy.

The magnitude of the effect of the horizontal transmission of culture is small, which may indicate that vertical transmission is more important in the transmission of culture. Of course, we recognize that this is not a full-proof method of identifying the transmission of culture, but it is comforting that our results suggest that immigrants are sensitive to their ethnic communities, which gives us additional empirical evidence that not only do laws and institutions affect women's decisions about how many children they have, but also that social norms may play an important role.

\section{CONCLUSIONS}

In recent decades, there has been a considerable decline in the fertility rates of many countries, with those rates reaching levels below the replacement rate in many developed countries (set at 2.1 children per woman), whereas in other countries, mainly developing countries, the fertility rate has remained quite high. This leads us to wonder whether economic conditions, laws, and institutions are the only factors affecting fertility behavior, or whether the fertility culture (social norms) may also be important. A cross-country analysis to explore this issue is not useful because of the interrelations between all these variables. Thus, in order to examine whether culture plays a role in fertility decisions, we have followed the epidemiological approach, using data on immigrant women arriving in 
the US when very young. All of these women grew up under the same US laws and institutions, so that the positive estimated relationship between the home-country mean number of children born and the number of children born to our sample may be interpreted as evidence that fertility culture plays a role in the fertility decision.

In contrast to prior works analyzing the effect of culture on fertility (Bellido et al. 2016; Fernández and Fogli 2006, 2009), our initial results suggest that the cultural effect can only explain a small part of the cross-country variations in the number of children born. This can be due to the fact that our sample of countries of origin has been considerably extended, including both developed and developing countries. If the epidemiological approach is appropriate in examining the cultural effect, this should not be an important issue, since our sample of women grew up under similar macroeconomic conditions in the US. In addition, other characteristics of the countries of origin (GDP per capita, FLFP, and unemployment rate) and the unobserved human capital that may vary between developed and developing countries do not appear to be driving our estimates. It could also be explained by the differences in the sample used, since earlier works focus on second-generation immigrants whereas we use information from young-arrival firstgeneration immigrants. However, the cultural impact decreases as generations pass, Marcén (2014), so by using a sample of first-generation immigrants, the cultural effect should be greater than that observed for second-generation immigrants. In any case, our sample of first-generation immigrants can be considered quite similar to a sample of second-generation immigrants, as Furtado et al. (2013) explain. A similar effect is detected when the cultural proxy is measured in different years, and by using several US Censuses (1970 to 1990), so this does not appear to be a factor in our estimated small cultural effect. The inclusion of husband's characteristics to the analysis, as in Fernández and Fogli (2009), does not substantially alter our findings, and does not appear to be a determinant of the small cultural effect. In our work, we show that the cause of the small cultural effect appears to be the way in which the cultural proxy is measured. One measure of culture for each country of origin appears not to be sufficient to measure fertility culture. The impact of culture considerably increases when the cultural proxy is more precisely measured within each country of origin, calculating the cultural proxy by age, education level, and employment status. This suggests that, depending on the women's characteristics, it is more or less socially acceptable to have more or fewer children, and that this may vary within and across countries. Thus, heterogeneity within countries 
should be considered as an important issue in studying the effect of culture on fertility decisions.

We also view our findings as evidence that cultural differences constitute a potential barrier to cross-country convergence in fertility rates. On the one hand, we find that fertility culture not only affects the number of children born, but also the decision to have children, or not. Our results show that the greater the home-country mean number of children born, the greater the number of women originating from those countries who will decide to have children, and among those who do decide to have children, the greater the home-country mean, the greater the number of children that women will have, whence it may be inferred that the fertility gap across countries may be maintained or even increased because of cultural differences. On the other hand, an examination of the horizontal transmission of culture appears to reveal that women living in the same ethnic communities, whose counterparts in their countries of origin have many children, tend to have more children in their host country, but this is not observed in the case of those immigrant women whose counterparts have few children. Thus, since women appear to be sensitive to the behavior of the communities in which they live, those living in countries where women have many children would be more likely to have many children and those living in countries with low fertility rates would be more likely to have few children, which may maintain the fertility gap across countries.

How can the fertility culture be changed? This is a tricky question. The special treatment (primarily economic) that families with 3 or more children enjoy, does not appear to encourage couples to have more children in developed countries. The ineffectiveness of pronatalist policies, Fanti and Gori (2011), has also been observed in the application of other policies, whose objective was also to reverse the negative trend of fertility rates, such as that enacted in Spain in 2007 (Law 35/2007), known as 'the baby check', but that only applied in a short period, from 2007 to 2010. In order to reduce population growth, policies of birth control were in effect in China between 1979 and 2015. Today, this policy has been partially removed, mainly because China has a significant need for workers. Nonetheless, the response of Chinese women to the change in the legislation does not appear to be what the Chinese government expected; indeed, the current fertility rates have not changed. After so many years of birth control, it could be expected that the social norms regarding fertility would have changed. Other measures have had unexpected impacts on the fertility decisions of women. Using the slogan "Do it for Mom!”, a Danish travel agency encouraged parents who want to be grandparents to 
pay for a vacation period for their children and their partners. Surprisingly, nine months later, there has been a considerable increase in the number of births in Denmark. It is unlikely that this will be maintained in the long run if the social norms in Denmark do not also change. Therefore, since culture appears to play a role in the fertility behavior of women, policy-makers should consider carefully which measures have the potential to change social norms, and should remember that culture changes slowly, so policies should be applied for long periods of time in order to have the desired effect.

\section{REFERENCES}

Adserà, A., and Ferrer, A. (2015). "Immigrants and demography: Marriage, divorce, and fertility”, Handbook of the economics of international migration, edited by Chiswick, B. R., and Miller, P. W. Elsevier, 1(7), 315-374.

Abma, J. C., and Martínez, G. M. (2006). "Childlessness among older women in the United States: Trends and profiles”, Journal of Marriage and Family, 68(4), 1045-1056.

Ahn, N., and Mira, P. (2002). “A note on the changing relationship between fertility and female employment rates in developed countries”, Journal of Population Economics, 15(4), 667-682.

Ananat, E., Gruber, J., and Levine, P. (2007). “Abortion legalization and life-cycle fertility”, Journal of Human Resources, 42(2), 375-397.

Münz, R., and Ulrich, R. (1997). “Changing patterns of immigration to Germany 19451995: ethnic origins demographic structure future prospects”. In migration and refugees: politics and policies in the United States and Germany, edited by Bade, K. J., and Weiner, M., Providence and Oxford: Berghahn Books, 1, 65-119

Barro, R., and Becker, G. (1988). “A Reformulation of the economic theory of fertility”, Quarterly Journal of Economics, 103(1), 1-25.

Barro, R. J., and Lee, J. W. (2013). “A new data set of educational attainment in the world, 1950-2010”, Journal of development economics, 104, 184-198.

Becker, G. (1981). “A treatise on the family”, Cambridge MA: Harvard University Press. 
Bellido, H., and Marcén, M. (2014). “Divorce laws and fertility”, Labour Economics, 27, 56-70.

Bellido, H., Marcén, M., and Molina, J.A. (2016). "The effect of culture on fertility behavior of US teen mothers”, Feminist Economics, 22(3), 101-126.

Bertrand, M., Luttmer, E. F. P., and Mullainathan, S. (2000). "Network effects and welfare cultures”, Quarterly Journal of Economics, 115(3), 1019-1055.

Blau, F. D., Kahn, L. M., Liu, A. Y. H., and Papps, K. L. (2013). "The transmission of women's fertility, human capital, and work orientation across immigrant generations”, Journal of Population Economics, 26(2), 405-435,

Breierova, L., and Duflo, E. (2004). “The impact of education on fertility and child mortality: Do fathers really matter less than mothers?”, National Bureau of Economic Research, Working Paper 10513.

Brewster, K., and Rindfuss, R. (2000). “Fertility and women’s employment in industrialized nations”, Annual Review of Sociology, 26(1), 271-296.

Contreras, D. and Plaza, G. (2010). “Cultural factors in women’s labor force participation in Chile”, Feminist Economics, 16(2), 27-46.

Cragg, J. (1971). "Some statistical models for limited dependent variables with application to the demand for durable goods”, Econometrica, 39(5), 829-844.

Day, C., and Guest, R. (2016). "Fertility and female wages: A new link via house prices”, Economic Modelling, 53, 121-132.

Doepke, M. (2005). “Child mortality and fertility decline: Does the Barro-Becker model fit the facts?”, Journal of Population Economics, 18(2), 337-366.

Doepke, M., and Kindermann, F. (2016). "Bargaining over babies: theory, evidence, and policy implications”, National Bureau of Economic Research, Working Paper 22072

Doepke, M., and Kindermann, F. (2017). “Intrahousehold decision making and fertility”, forcoming in Demographic Change and Long-Run Development, edited by Cervellati M., and Sunde U., MIT Press. 
Durand, J., Massey, D. S., and Parrado, E. A. (1999). “The new era of Mexican migration to the United States”, The Journal of American History, 86(2), 518-536.

Engelhardt, H., Kögel, T., and Prskawetz, A. (2004). "Fertility and women's employment reconsidered: A macro-level time-series analysis for developed countries, 1960-2000”, Population Studies, 58(1), 109-120.

Eugster, B., Lalive, R., Steinhauer, A., and Zweimüller, J. (2017). “Culture, work attitudes and job search: Evidence from the Swiss language border”, Journal of the European Economic Association, DOI: 10.1093/jeea/jvw024.

Fanti, L., and Gori, L. (2011). “Child policy ineffectiveness in an overlapping generations small open economy with human capital accumulation and public education”, Economic Modelling, 28(1), 404-409.

Fanti, L., and Spataro, L. (2013). “On the relationship between fertility and public national debt”, Economic Modelling, 33, 843-849.

Fernández, R. (2007). "Women, work, and culture”, Journal of the European Economic Association, 5(2-3), 305-332.

Fernández, R. (2011). “Does culture matter?”, Amsterdam, The Netherlands: NorthHolland: Handbook of Social Economics, edited by Benhabib J., Bisin A., and Jackson M.O., 1(11), 481-510.

Fernández, R., and Fogli A. (2006). "Fertility: the role of culture and family experience”, Journal of the European Economic Association, 4(2-3), 552-561.

Fernández, R., and Fogli, A. (2009). "Culture: an empirical investigation of beliefs, work, and fertility”, American Economic Journal: Macroeconomics, 1(1), 146-177.

Furtado, D., Marcén, M., and Sevilla, A.(2013). "Does culture affect divorce? Evidence from European immigrants in the United States”, Demography, 50(3), 1013-1038.

Galor, O., and Weil, D. (1996). “The gender gap, fertility and growth”, American Economic Review, 86(3), 374-387. 
Giuliano, P. (2007). "Living arrangements in western Europe: Does cultural origin matter?”, Journal of the European Economic Association, 5(5), 927-952.

Giuliano, P. (2016). "Review of cultural evolution: society, technology, language, and religion”, Journal of Economic Literature, 54(2), 522-533.

Greenwood, J., and Seshadri, A. (2002). “The U.S. demographic transition”, American Economic Review, 92(2), 153-159.

Goldin, C., and Katz, L. (2000). "Career and marriage in the age of the pill”, American Economic Review, 90(2), 461-465.

Goldin, C., and Katz, L. (2002). “The power of the pill: Oral contraceptives and women’s career and marriage decisions”, The Journal of Political Economic, 110(4), 730-770.

Guldi, M. (2008). "Fertility effects of abortion and birth control pill access for minors", Demography, 45(4), 817-827.

Kalwij, A. (2000). "The effects of female employment status on the presence and number of children”, Journal of Population Economics, 13(2), 221-239.

Leon, A. (2004). "The effect of education on fertility: evidence from compulsory schooling laws”, Unpublished manuscript, University of Pittsburgh.

Marcén, M. (2014).“The role of culture on self-employment”, Economic Modelling, 44(1), s20-s32.

Michael, R. (1985). "Consequences of the rise in female labor force participation rates: questions and probes”, Journal of Labor Economics, 3(1, Part 2), s117-s146.

Minnesota Population Center Integrated Public Use Microdata Series, International: Version 6.4 [Machine-readable database]. Minneapolis: University of Minnesota, (2015).

Nollenberger, N., Rodríguez, N., and Sevilla, A. (2016). “The math gender gap: The role of culture”, American Economic Review, 106(5), 257-261.

Ruggles, S., Genadek, K., Goeken, R., Grover, J., and Sobek, M.Integrated Public Use Microdata Series: Version 6.0 [Machine-readable database]. Minneapolis: University of Minnesota (2015). 
Sah, R. (1991). "The effect of child mortality changes on fertility choice and parental welfare”, Journal of Political Economy, 99(3), 582-606.

Sevilla, A. (2010). "Division of household labor and cross-country differences in household formation rates”, Journal of Population Economics, 23(1), 225-249.

Sorenson, A. M. (1989). 'Husbands' and wives' characteristics and fertility decisions: A diagonal mobility model”, Demography, 26(1), 125-135.

Tempo, C. J. B. (2008). “Americans at the gate: The United States and refugees during the Cold War”, Princeton NJ: Princeton University Press.

The Economist (2014). http://www.economist.com/news/international/21603024-whyshrinking-populations-may-be-no-bad-thing-quality-time

Thomson, E., McDonald, E., and Bumpass, L. L. (1990). "Fertility desires and fertility: Hers, his, and theirs”, Demography, 27(4), 579-588.

Tobin, J. (1958). "Estimation of relationships for limited dependent variables", Econometrica, 26 (1), 24-36.

United Nations Educational, Scientific and Cultural Organization (UNESCO) (2001). “Universal Declaration on Cultural Diversity”, $31^{\text {st }}$ Session of the General Conference of Unesco.

Willis, R. (1973). “A new approach to the economic theory of fertility behaviour”, Journal of Political Economy, 81(2), 14-64.

World Bank Data http://data.worldbank.org/

World Values Survey http://www.worldvaluessurvey.org/wvs.jsp 
Figure 1: Evolution of the total fertility rate from 1980 to 2014

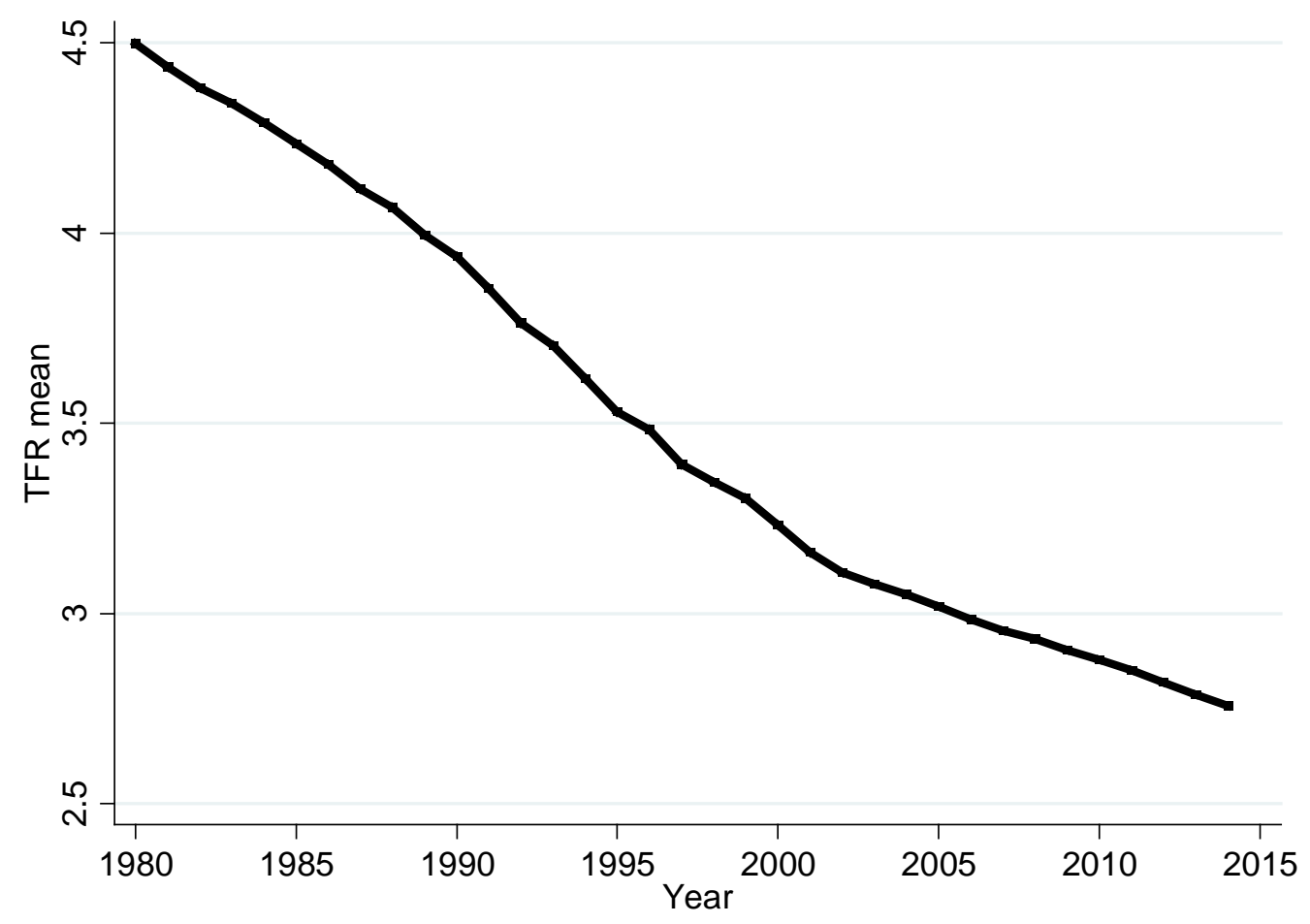

Notes: Data come from the World Bank. The mean TFR represented in this figure has been calculated using information on all countries with available data for the period considered. 
Figure 2: Relationship between the TFR in 1980 and the TFR in 2014, by country

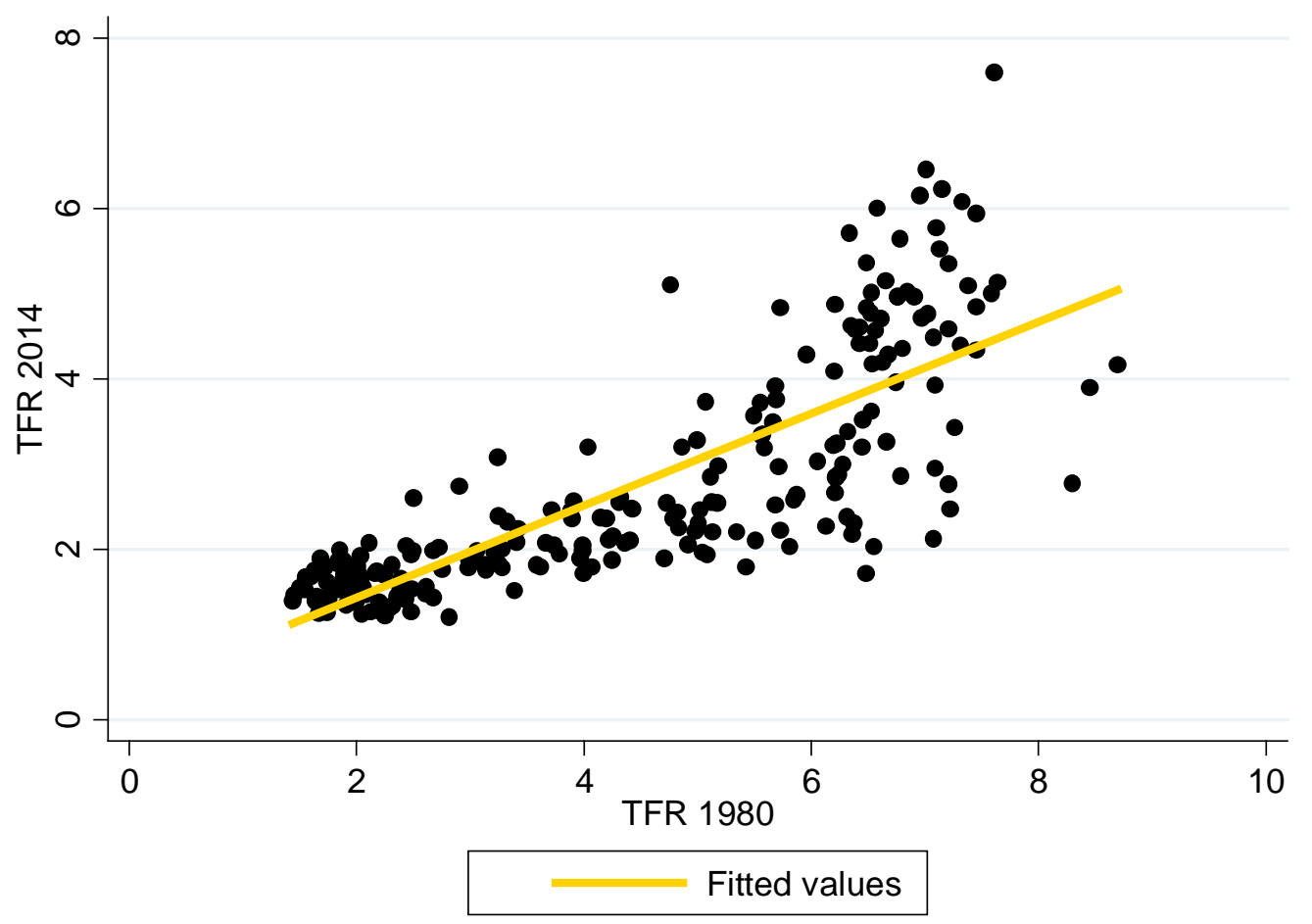

Notes: Data come from the World Bank. 
Figure 3: The number of children that immigrant women have in the US and the mean number of children born in their respective countries of origin

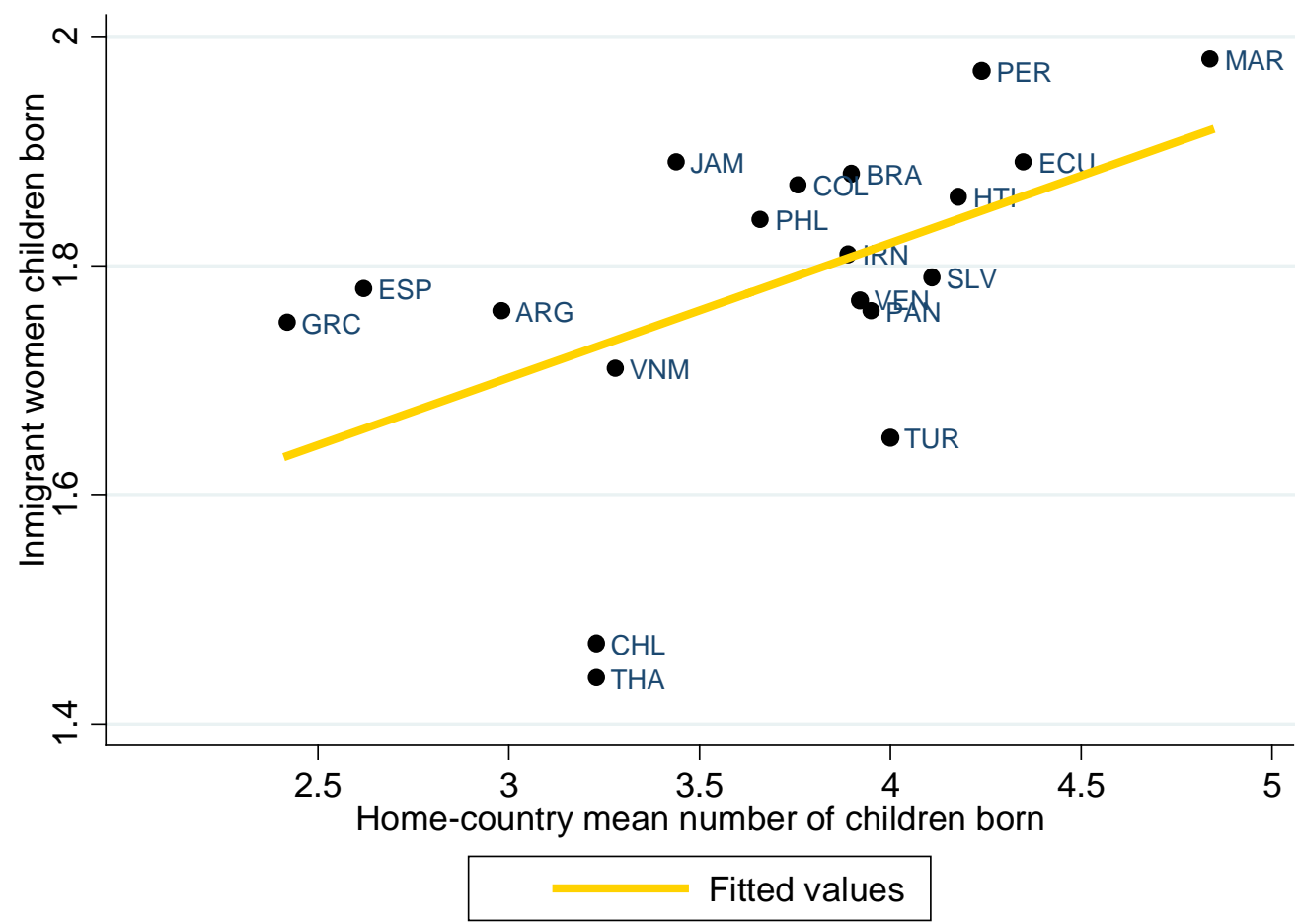

Notes: The home-country mean number of children born, calculated using data from the International IPUMS, is plotted on the x-axis, while the mean number of children per immigrant woman of those countries of origin, calculated using data from the 5\% IPUMS of the 1990 US Census, is plotted on the y-axis. Note that we include here only those countries of origin whose immigrant women living in the US have fewer than two children per woman, on average. 
Table 1: Summary statistics by country of origin

\begin{tabular}{|c|c|c|c|c|c|c|c|}
\hline Country of origin & $\begin{array}{c}\text { Home-country } \\
\text { mean number of } \\
\text { children born }\end{array}$ & $\begin{array}{c}\text { Immigrant } \\
\text { women children } \\
\text { born }\end{array}$ & Age & High School & Some college & More college & Observations \\
\hline Hungary & 2.14 & 2.28 & 35.52 & 0.31 & 0.28 & 0.31 & 29 \\
\hline Germany & 2.18 & 2.01 & 31.82 & 0.35 & 0.38 & 0.18 & 1,799 \\
\hline Austria & 2.28 & 2.07 & 38.19 & 0.24 & 0.35 & 0.37 & 68 \\
\hline Greece & 2.42 & 1.75 & 32.66 & 0.32 & 0.33 & 0.29 & 73 \\
\hline Spain & 2.62 & 1.78 & 27.69 & 0.42 & 0.30 & 0.19 & 108 \\
\hline Canada & 2.66 & 2.11 & 33.62 & 0.28 & 0.42 & 0.25 & 710 \\
\hline China & 2.91 & 2.57 & 35.73 & 0.14 & 0.29 & 0.39 & 51 \\
\hline Argentina & 2.98 & 1.76 & 29.88 & 0.34 & 0.28 & 0.36 & 50 \\
\hline Chile & 3.23 & 1.47 & 28.27 & 0.27 & 0.27 & 0.33 & 15 \\
\hline Thailand & 3.23 & 1.44 & 22.39 & 0.28 & 0.39 & 0.00 & 18 \\
\hline Vietnam & 3.28 & 1.71 & 26.83 & 0.29 & 0.42 & 0.08 & 24 \\
\hline Jamaica & 3.44 & 1.89 & 29.51 & 0.31 & 0.47 & 0.13 & 45 \\
\hline Philippines & 3.66 & 1.84 & 28.89 & 0.32 & 0.43 & 0.17 & 259 \\
\hline Colombia & 3.76 & 1.87 & 28.06 & 0.29 & 0.51 & 0.14 & 86 \\
\hline Iran & 3.89 & 1.81 & 34.06 & 0.13 & 0.31 & 0.50 & 16 \\
\hline Brazil & 3.90 & 1.88 & 32.58 & 0.32 & 0.20 & 0.44 & 50 \\
\hline Venezuela & 3.92 & 1.77 & 33.06 & 0.13 & 0.32 & 0.48 & 31 \\
\hline Panama & 3.95 & 1.76 & 33.54 & 0.31 & 0.36 & 0.30 & 118 \\
\hline Turkey & 4.00 & 1.65 & 27.35 & 0.32 & 0.29 & 0.26 & 34 \\
\hline El Salvador & 4.11 & 1.79 & 25.83 & 0.28 & 0.28 & 0.07 & 29 \\
\hline Haiti & 4.18 & 1.86 & 26.29 & 0.19 & 0.52 & 0.19 & 21 \\
\hline Peru & 4.24 & 1.97 & 31.00 & 0.24 & 0.55 & 0.16 & 38 \\
\hline Ecuador & 4.35 & 1.89 & 27.71 & 0.40 & 0.31 & 0.20 & 35 \\
\hline Mexico & 4.40 & 2.12 & 27.92 & 0.36 & 0.23 & 0.04 & 1,949 \\
\hline Nicaragua & 4.63 & 2.17 & 29.38 & 0.24 & 0.38 & 0.14 & 29 \\
\hline Morocco & 4.84 & 1.98 & 32.20 & 0.29 & 0.46 & 0.22 & 41 \\
\hline Mean & 3.28 & 2.03 & 30.40 & 0.33 & 0.33 & 0.16 & \\
\hline Std.dev & 0.98 & 1.12 & 7.16 & 0.47 & 0.47 & 0.36 & \\
\hline
\end{tabular}

Note: Countries of origin have been ordered from lowest to highest mean number of children born by country of origin, using data from the International IPUMS. The other descriptive statistics were constructed utilizing data from the 5\% microdata sample of the 1990 US Census, IPUMS USA. The sample contains 5,726 observations of immigrant women, aged 16 to 46, originating from 26 different countries. 
Table 2: The effect of culture on the number of children born

(Dependent Variable: Children born)

\begin{tabular}{lccc}
\hline \hline & $(1)$ & $(2)$ & $(3)$ \\
\cline { 2 - 4 } Sample: & \multicolumn{3}{c}{ Women aged 16-46 } \\
\hline HCCEB (Home-country mean number of children & $0.078^{* *}$ & $0.067^{*}$ & $0.068^{*}$ \\
born) & $(0.029)$ & $(0.034)$ & $(0.036)$ \\
Age & $0.185^{* * *}$ & $0.186^{* * *}$ & $0.185^{* * *}$ \\
& $(0.031)$ & $(0.030)$ & $(0.030)$ \\
Age $^{2} / 100$ & $-0.195^{* * *}$ & $-0.199^{* * *}$ & $-0.197^{* * *}$ \\
& $(0.036)$ & $(0.034)$ & $(0.033)$ \\
High School Graduate & $-0.386^{* * *}$ & $-0.375^{* * *}$ & $-0.361^{* * *}$ \\
& $(0.048)$ & $(0.048)$ & $(0.047)$ \\
Some college & $-0.651^{* * *}$ & $-0.647^{* * *}$ & $-0.637^{* * *}$ \\
& $(0.057)$ & $(0.057)$ & $(0.057)$ \\
More college & $-0.965^{* * *}$ & $-0.949^{* * *}$ & $-0.947^{* * *}$ \\
& $(0.096)$ & $(0.090)$ & $(0.083)$ \\
\hline State fixed effects & No & Yes & No \\
MSA fixed effects & No & No & Yes \\
Observations & 5,726 & 5,726 & 5,726 \\
$\mathrm{R}^{2}$ & 0.151 & 0.160 & 0.189 \\
\hline \hline
\end{tabular}

Notes: The home-country mean number of children born is calculated using information on women having at least one child, from the International IPUMS. The sample, obtained from the 5\% microdata sample of the 1990 US Census, consists of immigrant women aged 16 to 46 who arrived in the US at or below the age of 5, who report a country of origin, and who have at least one child. Estimates are weighted. Robust standard errors, clustered by country of origin, are in parentheses. *** Significant at the $1 \%$ level, ** Significant at the $5 \%$ level, * Significant at the $10 \%$ level. 
Table 3: The effect of culture on fertility by age

(Dependent Variable: Children born)

\begin{tabular}{|c|c|c|c|c|c|}
\hline \multirow[b]{2}{*}{ Sample: } & \multirow{2}{*}{\multicolumn{2}{|c|}{$\begin{array}{cc}(1) & (2) \\
\text { Women aged } 40-46\end{array}$}} & (3) & (4) & (5) \\
\hline & & & \multicolumn{3}{|c|}{ Women aged 20-46 } \\
\hline HCCEB & $\begin{array}{l}0.194^{* *} \\
(0.075)\end{array}$ & & $\begin{array}{l}0.075^{* *} \\
(0.034)\end{array}$ & & \\
\hline HCCEB for women aged 40-46 & & $\begin{array}{l}0.126^{* *} \\
(0.050)\end{array}$ & & & \\
\hline $\begin{array}{l}\text { HCCEB by age group } \\
(20-29,30-39,40-46)\end{array}$ & & & & $\begin{array}{c}0.101^{* * *} \\
(0.032)\end{array}$ & $\begin{array}{c}0.135^{* * *} \\
(0.024)\end{array}$ \\
\hline Age & $\begin{array}{c}-4.422 * * * \\
(1.004)\end{array}$ & $\begin{array}{c}-4.617^{* * * *} \\
(1.019)\end{array}$ & $\begin{array}{c}0.199 * * * \\
(0.029)\end{array}$ & $\begin{array}{c}0.186^{* * *} \\
(0.025)\end{array}$ & $\begin{array}{c}0.186^{* * *} \\
(0.030)\end{array}$ \\
\hline $\mathrm{Age}^{2} / 100$ & $\begin{array}{c}5.079 * * * \\
(1.161)\end{array}$ & $\begin{array}{c}5.310^{* * *} \\
(1.179)\end{array}$ & $\begin{array}{c}-0.216^{* * * *} \\
(0.033)\end{array}$ & $\begin{array}{c}-0.209 * * * \\
(0.033)\end{array}$ & $\begin{array}{c}-0.215^{* * * *} \\
(0.037)\end{array}$ \\
\hline High School Graduate & $\begin{array}{c}-0.769 * * * \\
(0.103)\end{array}$ & $\begin{array}{c}-0.763^{* * *} \\
(0.105)\end{array}$ & $\begin{array}{c}-0.434^{* * *} \\
(0.050)\end{array}$ & $\begin{array}{c}-0.434^{* * *} \\
(0.052)\end{array}$ & $\begin{array}{c}-0.406^{* * * *} \\
(0.061)\end{array}$ \\
\hline Some college & $\begin{array}{c}-1.273^{* * *} \\
(0.155)\end{array}$ & $\begin{array}{c}-1.263^{* * *} \\
(0.157)\end{array}$ & $\begin{array}{c}-0.702^{* * *} \\
(0.056)\end{array}$ & $\begin{array}{c}-0.704^{* * *} \\
(0.061)\end{array}$ & $\begin{array}{c}-0.666^{* * *} \\
(0.069)\end{array}$ \\
\hline More college & $\begin{array}{c}-1.403^{* * *} \\
(0.101)\end{array}$ & $\begin{array}{c}-1.397 * * * \\
(0.103)\end{array}$ & $\begin{array}{c}-1.008 * * * \\
(0.079)\end{array}$ & $\begin{array}{c}-1.007 * * * \\
(0.082)\end{array}$ & $\begin{array}{c}-0.952 * * * \\
(0.084)\end{array}$ \\
\hline State fixed effects & Yes & Yes & Yes & Yes & Yes \\
\hline Country of origin fixed effects & No & No & No & No & Yes \\
\hline Observations & 823 & 823 & 5,399 & 5,399 & 5,399 \\
\hline $\mathrm{R}^{2}$ & 0.194 & 0.194 & 0.154 & 0.156 & 0.165 \\
\hline
\end{tabular}

Notes: In column 1, the cultural proxy is calculated as in Table 2, while in the second column, the home-country mean number of children born has been calculated for women aged 40 to 46 having at least one child. The cultural proxy in column 3 coincides with that included in Table 2. In columns 4 and 5, the home-country mean number of children born has been calculated by country of origin and age group (20-29, 30-39, 40-46).. Estimates are weighted. Robust standard errors, clustered by country of origin, are in parentheses. ${ }^{* * *}$ Significant at the $1 \%$ level, ** Significant at the 5\% level, * Significant at the $10 \%$ level. 
Table 4: The impact of culture on fertility by age group, education level, and employment status

(Dependent Variable: Children born)

\begin{tabular}{|c|c|c|c|c|c|c|c|c|}
\hline \multirow[b]{2}{*}{ Sample: } & (1) & (2) & (3) & (4) & (5) & (6) & (7) & (8) \\
\hline & \multicolumn{6}{|c|}{ Women aged 20-46 } & \multicolumn{2}{|c|}{ Women aged 40-46 } \\
\hline HCCEB by age and education & $\begin{array}{c}0.186^{* * *} \\
(0.065)\end{array}$ & $\begin{array}{c}0.206^{* * *} \\
(0.035)\end{array}$ & & & & & & \\
\hline HCCEB & & & $\begin{array}{c}0.082 * * \\
(0.039)\end{array}$ & & & $\begin{array}{c}0.112 * * \\
(0.046)\end{array}$ & & \\
\hline HCCEB by age and employment & & & & $\begin{array}{c}0.211^{* * *} \\
(0.049)\end{array}$ & $\begin{array}{c}0.278^{* * *} \\
(0.030)\end{array}$ & & $\begin{array}{c}0.200 * * * \\
(0.066)\end{array}$ & $\begin{array}{c}0.362 * * * \\
(0.061)\end{array}$ \\
\hline Age & $\begin{array}{c}0.173^{* * *} \\
(0.029)\end{array}$ & $\begin{array}{c}0.177^{* * *} \\
(0.031)\end{array}$ & $\begin{array}{c}0.195^{* * * *} \\
(0.033)\end{array}$ & $\begin{array}{c}0.199 * * * \\
(0.018)\end{array}$ & $\begin{array}{c}0.195^{* * *} \\
(0.027)\end{array}$ & $\begin{array}{c}0.223^{* * *} \\
(0.016)\end{array}$ & $\begin{array}{c}-5.264 * * * \\
(1.395)\end{array}$ & $\begin{array}{c}-5.528 * * * \\
(1.548)\end{array}$ \\
\hline $\operatorname{Age}^{2} / 100$ & $\begin{array}{c}-0.192^{* * *} \\
(0.041)\end{array}$ & $\begin{array}{c}-0.200 * * * \\
(0.042)\end{array}$ & $\begin{array}{c}-0.206 * * * \\
(0.041)\end{array}$ & $\begin{array}{c}-0.237 * * * \\
(0.027)\end{array}$ & $\begin{array}{c}-0.242 * * * \\
(0.036)\end{array}$ & $\begin{array}{c}-0.245^{* * *} \\
(0.019)\end{array}$ & $\begin{array}{c}6.071^{* * *} \\
(1.609)\end{array}$ & $\begin{array}{c}6.368 * * * \\
(1.788)\end{array}$ \\
\hline High School Graduate & $\begin{array}{c}-0.266^{* * *} \\
(0.073)\end{array}$ & $\begin{array}{c}-0.209 * * * \\
(0.035)\end{array}$ & $\begin{array}{c}-0.434 * * * \\
(0.050)\end{array}$ & $\begin{array}{c}-0.428 * * * \\
(0.050)\end{array}$ & $\begin{array}{c}-0.394 * * * \\
(0.064)\end{array}$ & $\begin{array}{c}-0.447 * * * \\
(0.053)\end{array}$ & $\begin{array}{c}-0.703^{* * *} \\
(0.139)\end{array}$ & $\begin{array}{c}-0.630 * * * \\
(0.175)\end{array}$ \\
\hline Some college & $\begin{array}{c}-0.520 * * * \\
(0.076)\end{array}$ & $\begin{array}{c}-0.436 * * * \\
(0.048)\end{array}$ & $\begin{array}{c}-0.711^{* * *} \\
(0.064)\end{array}$ & $\begin{array}{c}-0.694 * * * \\
(0.057)\end{array}$ & $\begin{array}{c}-0.644 * * * \\
(0.070)\end{array}$ & $\begin{array}{c}-0.721 * * * \\
(0.056)\end{array}$ & $\begin{array}{c}-1.066 * * * \\
(0.201)\end{array}$ & $\begin{array}{c}-0.917^{* * *} \\
(0.280)\end{array}$ \\
\hline More college & $\begin{array}{c}-0.814^{* * *} \\
(0.068)\end{array}$ & $\begin{array}{c}-0.720 * * * \\
(0.031)\end{array}$ & $\begin{array}{c}-1.011 * * * \\
(0.073)\end{array}$ & $\begin{array}{c}-1.041^{* * *} \\
(0.063)\end{array}$ & $\begin{array}{c}-0.975 * * * \\
(0.077)\end{array}$ & $\begin{array}{c}-1.060 * * * \\
(0.065)\end{array}$ & $\begin{array}{c}-1.306^{* * *} \\
(0.148)\end{array}$ & $\begin{array}{c}-1.068^{* * *} \\
(0.227)\end{array}$ \\
\hline State fixed effects & Yes & Yes & Yes & Yes & Yes & Yes & Yes & Yes \\
\hline Country of origin fixed effects & No & Yes & No & No & Yes & No & No & Yes \\
\hline Observations & 4,635 & 4,635 & 4,635 & 3,634 & 3,634 & 3,634 & 540 & 540 \\
\hline $\mathrm{R}^{2}$ & 0.164 & 0.174 & 0.162 & 0.191 & 0.203 & 0.179 & 0.230 & 0.266 \\
\hline
\end{tabular}

Notes: The home-country mean number of children born is defined by age, education level, and country of origin in columns 1 and 2. Columns 3 and 6 use the same cultural proxy as in Table 2 for the sample of women of columns 1 and 2 and for the sample of women of columns 4 and 5, respectively. In columns 4 and 5, the home-country mean number of children born is calculated by age group, employment status, and country of origin. Columns 7 and 8 incorporate immigrant women aged 40 to 46 and the cultural proxy is measured by age, employment status, and country of origin. Estimates are weighted. Robust standard errors, clustered by country of origin, are in parentheses. *** Significant at the $1 \%$ level, ** Significant at the $5 \%$ level, * Significant at the $10 \%$ level. 
Table 5: Simple robustness checks

(Dependent Variable: Children born)

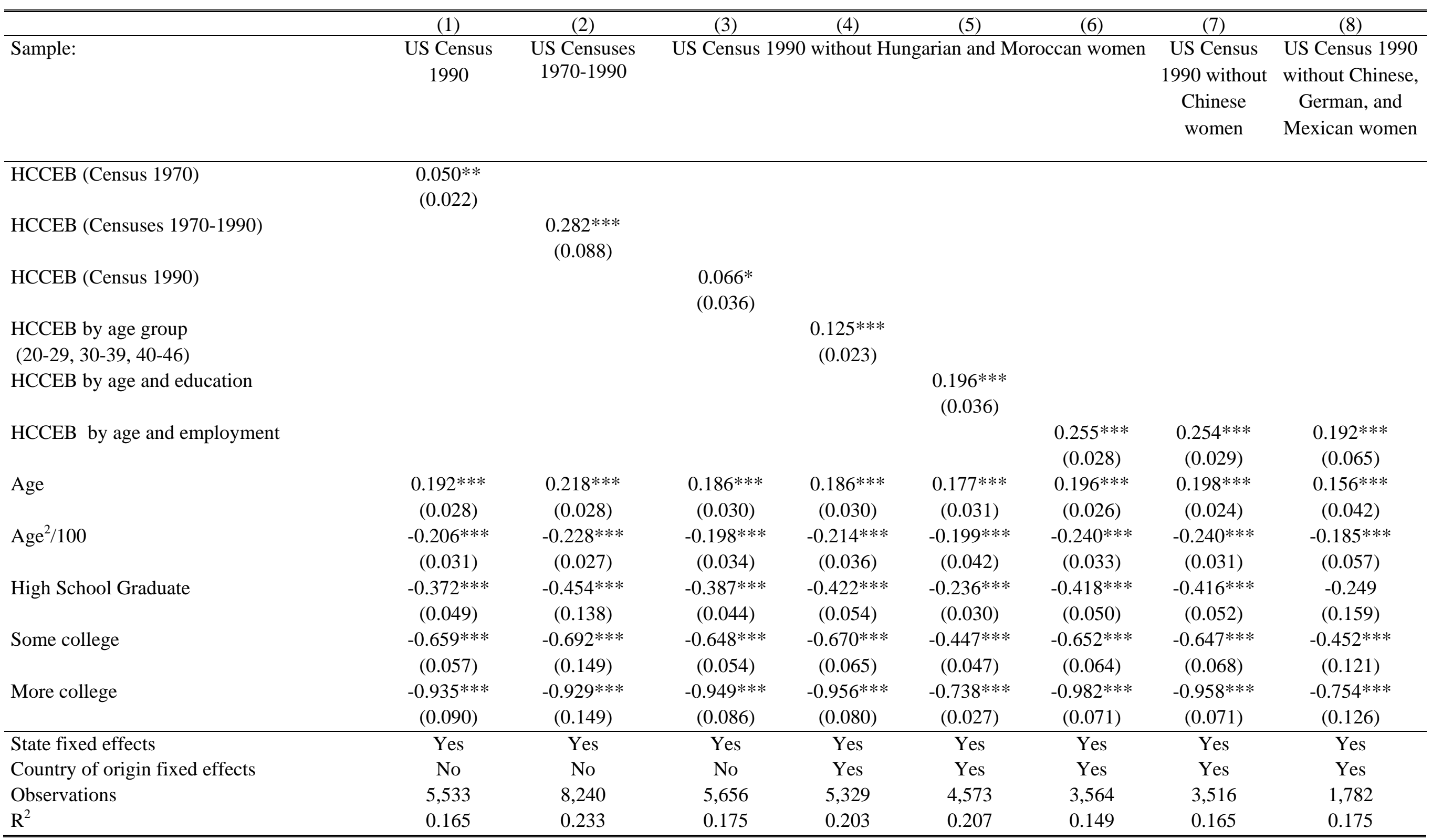

Notes: The home-country mean number of children born is calculated for 21 International Censuses of 1970 (those containing information in the 1970s) in column 1. In column 2, the $1 \%$ microdata of the 1970 US Census (796 observations, 21 countries of origin) and 5\% microdata of the 1980 US Census (1,718 observations, 32 countries of origin), is included in addition to the 5\% microdata sample of the 1990 US Census (5,726 observations, 26 countries of origin).In the rest of the columns, we use the sample obtained from the 5\% microdata sample of the 1990 US Census.We have excluded those immigrant women from Hungary and Morocco in columns 3 to 6, in which the home-country mean number of children born is defined as in table 2, by age group, by age group and education level, and by age group and employment status, respectively. Column 7 excludes immigrant women from China, and column 8 excludes those from China, Mexico, and Germany. Estimates are weighted. Robust standard errors, clustered by country of origin, are in parentheses. ${ }^{* *}$ Significant at the $1 \%$ level, ** Significant at the $5 \%$ level, * Significant at the $10 \%$ level. 
Table 6: More robustness checks, adding home-country observable characteristics, unobserved human capital, and redefining the cultural proxy using the World Values Survey

(Dependent Variable: Children born)

\section{(1)}

$0.113^{* * *}$

HCCEB

(0.029)

HCCEB by age group

(20-29, 30-39, 40-46)

HCCEB by age and education

HCCEB by age and employment

Home-country ideal number of children

$$
\text { Age }
$$

Age2/100

High School Graduate

Some college

More college

GDP pc

Female labor force participation

Total fertility rate

Unemployment rate

Human Capital

State fixed effects

Country fixed effects

Observations

R2

(0.064)

0.370

(0.277)

(0.047)

$-0.011^{*}$

(0.006)

$-0.025 *$

(0.013)
(2)

(3)

(4)

(5)

(6)

$0.139 * * *$
$(0.023)$

$0.189 * * *$

(0.045)

$0.266^{* * *}$

(0.030)

$$
\begin{array}{cc}
1.400 * * * & 0.684 * * * \\
(0.303) & (0.218) \\
0.172 * * * & 0.184 * * * \\
(0.019) & (0.021) \\
-0.193 * * * & -0.194 * * * \\
(0.014) & (0.020) \\
-0.402 * * * & -0.437 * * * \\
(0.056) & (0.042) \\
-0.662 * * * & -0.711^{* * *} \\
(0.066) & (0.050) \\
-0.945 * * * & -1.002 * * * \\
(0.085) & (0.076) \\
& 0.004 \\
& (0.008)
\end{array}
$$

$\begin{array}{llll}-0.358 * * * & -0.421 * * * & -0.246 * * * & -0.409 * * *\end{array}$

$\begin{array}{cc}(0.054) & (0.053) \\ -0.627 * * * & -0.686 * * *\end{array}$

(0.046)

$(0.054)$

$-0.666 * * *$

$(0.061)$

(0.055)

(0.058)

$\begin{array}{llll}-0.920 * * * & -0.982 * * * & -0.780 * * * & -1.013 * * *\end{array}$

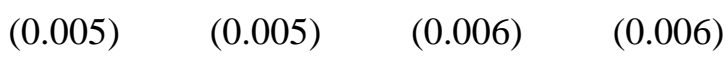

$-0.002$

1.939

1.215

1.802

$(0.004)$

(3.171)

(3.480)

(3.396)

0.042

$(0.055)$

$-0.001$

$-0.051$

(0.100)

-0.014 *

(0.062)

(0.063)

$-0.012$

(0.007)

$-0.015^{* *}$

$-0.015 * *$

(0.009)

$-0.005$

(0.007)

(0.006)

0.037

(0.015)

$-0.029$

0.020

(0.023)

\begin{tabular}{cccccc} 
Yes & Yes & Yes & Yes & Yes & Yes \\
No & No & No & No & Yes & No \\
5,726 & 5,399 & 4,635 & 3,634 & 5,008 & 5,008 \\
0.163 & 0.159 & 0.167 & 0.195 & 0.174 & 0.163 \\
\hline
\end{tabular}

Notes: In column 1, the home-country mean number of children born is calculated as in Table 2. In column 2, that variable has been measured by country of origin and age group. In column 3, it has been measured by country of origin, age group and education level, and in column 4 the cultural proxy has been calculated by country of origin, age group and employment status. In columns 5 and 6 , the home-country mean number of children born is replaced by the ideal number of children (WVS) as our proxy of culture. The number of observations of columns 5 and 6 changes because there is no available information for Austria, Ecuador, Greece, Haiti, Jamaica, Nicaragua and Panama in the WVS. Estimates are weighted. Robust standard errors, clustered by country of origin, are in parentheses. *** Significant at the $1 \%$ level, ** Significant at the $5 \%$ level, * Significant at the $10 \%$ level. 
Table 7: More robustness checks, adding characteristics of women's husbands

(Dependent Variable: Children born)

\begin{tabular}{|c|c|c|c|c|}
\hline & (1) & $(2)$ & (3) & (4) \\
\hline HCCEB by age & $\begin{array}{c}0.125^{* * *} \\
(0.032)\end{array}$ & & & \\
\hline Same $x$ HCCEB by age & & $\begin{array}{c}0.116^{* * *} \\
(0.027)\end{array}$ & $\begin{array}{c}0.119 * * \\
(0.046)\end{array}$ & $\begin{array}{c}0.136 * * \\
(0.050)\end{array}$ \\
\hline Not same $\mathrm{x}$ wife's HCCEB by age & & $\begin{array}{c}0.071 * * \\
(0.026)\end{array}$ & & $\begin{array}{c}0.066^{* *} \\
(0.025)\end{array}$ \\
\hline Not same $x$ husband's HCCEB by age & & & $\begin{array}{c}0.094 \\
(0.070)\end{array}$ & $\begin{array}{c}0.038 \\
(0.067)\end{array}$ \\
\hline Age & $\begin{array}{c}0.212^{* * *} \\
(0.039)\end{array}$ & $\begin{array}{c}0.214^{* * *} \\
(0.032)\end{array}$ & $\begin{array}{c}0.211^{* * *} \\
(0.030)\end{array}$ & $\begin{array}{c}0.211^{* * *} \\
(0.029)\end{array}$ \\
\hline $\mathrm{Age}^{2} / 100$ & $\begin{array}{c}-0.245^{* * *} \\
(0.047)\end{array}$ & $\begin{array}{c}-0.240^{* * *} \\
(0.041)\end{array}$ & $\begin{array}{c}-0.234^{* * *} \\
(0.038)\end{array}$ & $\begin{array}{c}-0.238 * * * \\
(0.039)\end{array}$ \\
\hline High School Graduate & $\begin{array}{c}-0.385^{* * *} \\
(0.044)\end{array}$ & $\begin{array}{c}-0.390 * * * \\
(0.040)\end{array}$ & $\begin{array}{c}-0.395^{* * *} \\
(0.039)\end{array}$ & $\begin{array}{c}-0.390 * * * \\
(0.040)\end{array}$ \\
\hline Some college & $\begin{array}{c}-0.591^{* * *} \\
(0.040)\end{array}$ & $\begin{array}{c}-0.595^{* * *} \\
(0.037)\end{array}$ & $\begin{array}{c}-0.601^{* * *} \\
(0.036)\end{array}$ & $\begin{array}{c}-0.596 * * * \\
(0.037)\end{array}$ \\
\hline More college & $\begin{array}{c}-0.878 * * * \\
(0.057)\end{array}$ & $\begin{array}{c}-0.895 * * * \\
(0.052)\end{array}$ & $\begin{array}{c}-0.899 * * * \\
(0.053)\end{array}$ & $\begin{array}{c}-0.895 * * * \\
(0.052)\end{array}$ \\
\hline Husband High School Graduate & $\begin{array}{c}-0.204 * * * \\
(0.044)\end{array}$ & $\begin{array}{c}-0.190 * * * \\
(0.044)\end{array}$ & $\begin{array}{c}-0.199 * * * \\
(0.046)\end{array}$ & $\begin{array}{c}-0.191^{* * *} \\
(0.044)\end{array}$ \\
\hline Husband Some college & $\begin{array}{c}-0.214^{* * *} \\
(0.056)\end{array}$ & $\begin{array}{c}-0.192^{* * *} \\
(0.039)\end{array}$ & $\begin{array}{c}-0.197 * * * \\
(0.042)\end{array}$ & $\begin{array}{c}-0.193 * * * \\
(0.041)\end{array}$ \\
\hline Husband More college & $\begin{array}{c}-0.264^{* * *} \\
(0.040)\end{array}$ & $\begin{array}{c}-0.247^{* * *} \\
(0.040)\end{array}$ & $\begin{array}{c}-0.256^{* * *} \\
(0.040)\end{array}$ & $\begin{array}{c}-0.249 * * * \\
(0.040)\end{array}$ \\
\hline Husband Total Income & $\begin{array}{c}0.057 \\
(0.066)\end{array}$ & $\begin{array}{c}0.065 \\
(0.064)\end{array}$ & $\begin{array}{c}0.057 \\
(0.068)\end{array}$ & $\begin{array}{c}0.066 \\
(0.064)\end{array}$ \\
\hline Husband Age & $\begin{array}{l}-0.002 \\
(0.008)\end{array}$ & $\begin{array}{l}-0.002 \\
(0.008)\end{array}$ & $\begin{array}{l}-0.002 \\
(0.008)\end{array}$ & $\begin{array}{l}-0.002 \\
(0.008)\end{array}$ \\
\hline Husband Age $^{2} / 100$ & $\begin{array}{l}-0.005 \\
(0.011)\end{array}$ & $\begin{array}{l}-0.005 \\
(0.010)\end{array}$ & $\begin{array}{l}-0.005 \\
(0.010)\end{array}$ & $\begin{array}{l}-0.005 \\
(0.010)\end{array}$ \\
\hline State fixed effects & Yes & Yes & Yes & Yes \\
\hline Country of origin fixed effects & Yes & No & No & No \\
\hline Observations & 4,198 & 4,198 & 4,198 & 4,198 \\
\hline $\mathrm{R}^{2}$ & 0.182 & 0.176 & 0.175 & 0.176 \\
\hline
\end{tabular}

Notes: The home-country mean number of children born is defined by age, and country of origin. All columns include characteristics of women's husbands such as age, level of education, and total income. The variation in the sample size is due to the availability of information for women's partners. In column 2, 3, and 4 we study the effect of husband's culture. Estimates are weighted. Robust standard errors, clustered by country of origin, are in parentheses. *** Significant at the $1 \%$ level, ** Significant at the 5\% level, * Significant at the $10 \%$ level. 
Table 8: The effect of culture on the decision to have children, and if so, how many

\begin{tabular}{|c|c|c|c|c|}
\hline & $(1)$ & $(2)$ & (3) & (4) \\
\hline & Tobit model & Tobit model & \multicolumn{2}{|c|}{ Cragg's double hurdle model } \\
\hline & & & First & Second \\
\hline & & & Stage & Stage \\
\hline \multirow[t]{2}{*}{ HCCEB by age } & $0.146 * * *$ & $0.130 * * *$ & $0.085^{* *}$ & $0.121 * * *$ \\
\hline & $(0.041)$ & $(0.032)$ & $(0.035)$ & $(0.031)$ \\
\hline \multirow[t]{2}{*}{ Age } & $0.659 * * *$ & $0.655^{* * *}$ & $0.399 * * *$ & $0.252 * * *$ \\
\hline & $(0.055)$ & $(0.053)$ & $(0.031)$ & $(0.043)$ \\
\hline \multirow[t]{2}{*}{$\operatorname{Age}^{2} / 100$} & $-0.809 * * *$ & $-0.802 * * *$ & $-0.492 * * *$ & $-0.291 * * *$ \\
\hline & $(0.070)$ & $(0.071)$ & $(0.041)$ & $(0.058)$ \\
\hline \multirow[t]{2}{*}{ High School Graduate } & $-1.088 * * *$ & $-1.059 * * *$ & $-0.748 * * *$ & $-0.541^{* * *}$ \\
\hline & $(0.072)$ & $(0.062)$ & $(0.053)$ & $(0.069)$ \\
\hline \multirow[t]{2}{*}{ Some college } & $-1.850 * * *$ & $-1.823 * * *$ & $-1.231 * * *$ & $-0.871 * * *$ \\
\hline & $(0.130)$ & $(0.111)$ & $(0.105)$ & $(0.091)$ \\
\hline \multirow[t]{2}{*}{ More college } & $-2.797 * * *$ & $-2.731 * * *$ & $-1.804 * * *$ & $-1.273 * * *$ \\
\hline & $(0.168)$ & $(0.138)$ & $(0.113)$ & $(0.137)$ \\
\hline State fixed effects & No & Yes & No & No \\
\hline Observations & 9,817 & 9,817 & 9,817 & 9,817 \\
\hline
\end{tabular}

Notes: The home-country mean number of children born has been defined by age group as in Table 3. In contrast to previous estimates, the sample selection includes immigrant women having no children. Columns 1 and 2 show the results of the estimation of a Tobit model, with and without fixed effects, respectively. Columns 3 and 4 report the estimates of a Cragg's double hurdle model. Estimates are weighted. Robust standard errors, clustered by country of origin, are in parentheses. $* * *$ Significant at the $1 \%$ level, ** Significant at the $5 \%$ level, * Significant at the $10 \%$ level. 
Table 9: Horizontal transmission of culture and the number of children born

(Dependent Variable: Children born)

\begin{tabular}{lcccc}
\hline \hline & $(1)$ & $(2)$ & $(3)$ & $(4)$ \\
\hline Proportion of women of the same origin by MSA & $-0.132^{* * *}$ & $-0.138^{* * *}$ & $-0.654^{* * *}$ & $-0.856^{* * *}$ \\
& $(0.028)$ & $(0.032)$ & $(0.207)$ & $(0.152)$ \\
HCCEB by age & & $0.136^{* * *}$ & 0.065 & \\
& & $(0.024)$ & $(0.041)$ & \\
Proportion of women of the same origin by MSA x & & & $0.167^{* *}$ & $0.233^{* * *}$ \\
HCCEB by age & & & $(0.070)$ & $(0.058)$ \\
Age & $0.204^{* * *}$ & $0.185^{* * *}$ & $0.185^{* * *}$ & $0.190^{* * *}$ \\
& $(0.028)$ & $(0.030)$ & $(0.030)$ & $(0.028)$ \\
Age $/ 100$ & $-0.225^{* * *}$ & $-0.215^{* * *}$ & $-0.212^{* * *}$ & $-0.214^{* * *}$ \\
& $(0.031)$ & $(0.037)$ & $(0.037)$ & $(0.034)$ \\
High School Graduate & $-0.408^{* * *}$ & $-0.407^{* * *}$ & $-0.409^{* * *}$ & $-0.409^{* * *}$ \\
& $(0.061)$ & $(0.060)$ & $(0.060)$ & $(0.060)$ \\
Some college & $-0.665^{* * *}$ & $-0.667^{* * *}$ & $-0.668^{* * *}$ & $-0.668^{* * *}$ \\
& $(0.066)$ & $(0.068)$ & $(0.067)$ & $(0.066)$ \\
More college & $-0.955^{* * *}$ & $-0.955^{* * *}$ & $-0.950^{* * *}$ & $-0.948^{* * *}$ \\
& $(0.084)$ & $(0.084)$ & $(0.082)$ & $(0.081)$ \\
\hline State fixed effects & Yes & Yes & Yes & Yes \\
Country of origin fixed effects & Yes & Yes & Yes & Yes \\
Observations & 5,399 & 5,399 & 5,399 & 5,399 \\
$\mathrm{R}^{2}$ & 0.162 & 0.165 & 0.166 & 0.165 \\
\hline \hline
\end{tabular}

Notes: The home-country mean number of children born has been calculated by country of origin and age group. Estimates are weighted. Robust standard errors, clustered by country of origin, are in parentheses. *** Significant at the $1 \%$ level, ** Significant at the $5 \%$ level, * Significant at the $10 \%$ level. 


\section{Appendix}

Table A1 Census

\begin{tabular}{|c|c|c|c|}
\hline Country & $\begin{array}{c}1990 \text { Census } \\
\text { Year } \\
\text { (IPUMS } \\
\text { International) }\end{array}$ & $\begin{array}{c}1980 \text { Census } \\
\text { Year } \\
\text { (IPUMS } \\
\text { International) }\end{array}$ & $\begin{array}{c}1970 \text { Census } \\
\text { Year } \\
\text { (IPUMS } \\
\text { International) }\end{array}$ \\
\hline Argentina & 1991 & 1980 & 1970 \\
\hline Armenia & - & 2001 & - \\
\hline Austria & 1991 & 1981 & 1981 \\
\hline Brazil & 1991 & 1980 & 1970 \\
\hline Byelorussia & - & 1990 & - \\
\hline Canada & 1991 & 1981 & 1971 \\
\hline Chile & 1992 & 1982 & 1970 \\
\hline China & 1990 & 1982 & 1982 \\
\hline Colombia & 1993 & 1985 & - \\
\hline Ecuador & 1990 & 1982 & 1974 \\
\hline El Salvador & 1992 & 1992 & 1992 \\
\hline Germany & 1981 & 1981 & 1971 \\
\hline Greece & 1991 & 1991 & 1991 \\
\hline Guinea & - & 1996 & - \\
\hline Haiti & 1982 & 1982 & - \\
\hline Hungary & 1990 & 1980 & 1970 \\
\hline Indonesia & - & 1980 & - \\
\hline Iran & 2006 & 2006 & 2006 \\
\hline Iraq & - & 1997 & - \\
\hline Jamaica & 1991 & 1982 & 1982 \\
\hline Mexico & 1990 & 1990 & 1970 \\
\hline Morocco & 1994 & 1982 & - \\
\hline Nicaragua & 1995 & 1971 & - \\
\hline Panama & 1990 & 1980 & 1970 \\
\hline Peru & 1993 & 1993 & 1993 \\
\hline Philippines & 1990 & 1990 & 1990 \\
\hline Romania & - & 1977 & 1977 \\
\hline Spain & 1991 & 1981 & 1981 \\
\hline Thailand & 1990 & - & - \\
\hline Turkey & 1990 & 1985 & 1985 \\
\hline Ukraine & - & 2001 & 2001 \\
\hline Venezuela & 1990 & 1990 & - \\
\hline Vietnam & 1989 & 1989 & - \\
\hline
\end{tabular}

Notes: This table shows the sample of countries of origin utilized to build the cultural proxy of our analysis, that is, home-country mean number of children born. 